\title{
LAS MEDIDAS EN LOS TEXTOS ESCOLARES DE MATEMÁTICAS EN LA VENEZUELA DECIMONÓNICA
}

\author{
Walter O. Beyer K. \\ nowarawb@gmail.com \\ Universidad Nacional Abierta
}

Recibido: 18/10/2019 Aceptado: 13/01/2020

\section{Resumen}

Este trabajo consiste en historiar la introducción y difusión del Sistema Metrico Decimal (SMD) en la Venezuela decimonónica. Se centró en el análisis de los libros escolares usados en la época, complementada con la consulta de diversos documentos (legales, curriculares, etc.). Se consideraron los contextos económico, socio-político y educativo del momento, para interpretar los hechos. El estudio se ubica en el área de la Historia de la Educación Matemática. Es una investigación de corte histórico-crítico, de base documental. La metodología empleada es de tipo cualitativo, siguiendo el método histórico. Los documentos base fueron sometidos a la crítica interna y externa. Las fuentes base privilegiadas fueron las primarias. Se partió de una síntesis histórica de la evolución de las medidas a nivel mundial, bajo una óptica antropomatemática; así como se consideró su evolución en Venezuela. Se emplearon como herramientas diversos constructos teóricos (Transposición Didáctica, disciplina escolar, etc.) tomados del mundo educativo. Se muestran relaciones entre los contextos y la evolución de los sistemas de medidas y, nexos entre la Transposición Didáctica y estos. Se muestran razones socio-políticas que impidieron la difusión del SMD una vez aprobado legalmente; se señalan personas e instituciones, así como influencias foráneas, que incidieron poderosamente en su introducción.

Palabras clave: Historia de la educación matemática, libros de texto de matemáticas, Sistema

Métrico Decimal

\section{MEASURES IN SCHOOL MATH TEXTS IN DECIMONICA VENEZUELA}

\begin{abstract}
This work consists in analyze the introduction and dissemination of the Decimal Metric System (DMS) in the Venezuelan nineteenth-century. It's focused on the analysis of school books used at that time, and complemented by consulting other documents (legal, curricular, etc.). The economic, socio-political and educational contexts of the moment were considered to interpret the historical facts. The study is located in the area of the History of Mathematics Education. It's a historical-critical research, documentary based. It was used a qualitative methodology, following the historical method. Base documents were submitted to internal and external criticism. The privileged base sources were the primary ones. It was based on a historical synthesis of the evolution of the measures worldwide, under an anthropomathematical perspective; as well as its evolution in Venezuela was considered. Various theoretical constructs (Didactic Transposition, school discipline, etc.) taken from the educational world, and others, were used as tools. A relationship between the contexts and the
\end{abstract}


evolution of the measurement systems are shown, and links between the Didactic Transposition and these. Socio-political reasons are shown that prevented the dissemination of the DMS once legally approved; people and institutions are pointed out, as well as foreign influences, which strongly influenced their introduction.

Keywords: History of Mathematics Education, Mathematics textbooks, Decimal Metric System

\title{
AS MEDIDAS EM TEXTOS DE MATEMÁTICA ESCOLAR NA DECIMONICA VENEZUELA
}

\begin{abstract}
Resumo
Este trabalho consiste em registrar a introdução e disseminação do Sistema Métrico Decimal (SMD) na Venezuela do século XIX. Centrou-se na análise dos livros escolares utilizados na época, complementada pela consulta de vários documentos (legais, curriculares, etc.). Os contextos econômico, sócio-político e educacional do momento foram considerados para interpretar os fatos. $\mathrm{O}$ estudo está localizado na área da História da Educação Matemática. É uma pesquisa documental, histórica e crítica. A metodologia utilizada é de tipo qualitativo, seguindo o método histórico. Os documentos de base foram submetidos a críticas internas e externas. As fontes de base privilegiadas foram as principais. $\mathrm{O}$ ponto de partida foi uma síntese histórica da evolução das medições em todo o mundo, de uma perspectiva antropomatemática; bem como sua evolução na Venezuela. Vários construtos teóricos (Transposição Didática, disciplina escolar, etc.) retirados do mundo educacional foram utilizados como ferramentas. São mostradas relações entre os contextos e a evolução dos sistemas de medição, bem como os vínculos entre a Transposição Didática e estes. Mostramse razões sócio-políticas que impediram a divulgação do SMD, uma vez que este foi legalmente aprovado; pessoas e instituições são indicadas, bem como influências estrangeiras, que influenciaram fortemente sua introdução.
\end{abstract}

Palavras-chave: História da Educação Matemática, Livros Didáticos de Matemática, Sistema Métrico Decimal.

\section{Introducción}

Los estudios antropológicos y arquelógicos han determinado claramente que los seres humanos, desde tiempos inmemoriales, han sentido la necesidad de medir, y es por ello que nuestra especie, el Homo sapiens -y posiblemente otras como algunos antecesores del hombre actual-, hayan creado mecanismos para ello, muchos de los cuales se han perdido en la bruma del tiempo; es decir, la actividad de medir es consubstancial al hombre, aunque también se ha podido establecer que otras especies del reino animal, aunque de manera limitada, tienen ciertas capacidades para emplear algún tipo de medición. Esta última particularidad se encuentra presente, por ejemplo, en las abejas. Ésta y otras habilidades de estos insectos fueron estudiadas, ya en las primeras décadas del siglo XX, por el etólogo y Premio Nobel 
Karl von Frish a través de lo que se conoce como la danza de las abejas. La actualización de éstos y otros estudios, referidos a sociedades de insectos como las hormigas y las abejas, pueden encontrarse en Hölldobler y Wilson (2014).

Sin embargo, se debe ser sumamente cuidadoso con respecto a las afirmaciones acerca de las capacidades de algunas especies animales de hacer ciertos procesamientos que se consideran "matemáticos", no sobredimensionando dichas capacidades.

Buena parte de la diferenciación entre la capacidad de los seres humanos y la de otras especies a efectos de la actividad de medición (y de otras como contar, localizar, etc.) deriva del hecho de que el Homo sapiens fue capaz de pasar de lo perceptual a lo conceptual, por medio de procesos de abstracción.

En este sentido, es bueno recordar lo planteado por Mosterin (1981), quien hace una importante distinción entre perceptos y conceptos. Señala éste que "los preconceptos perceptuales o perceptos son los patrones o plantillas de nuestro sistema neurosensorial, que nos permiten identificar formas perceptuales cada vez que se presentan en el continuo de nuestras sensaciones" (p. 13). En otro nivel están los conceptos que este autor clasifica en: ordinarios, científicos y teóricos.

[Los conceptos ordinarios] son las unidades de representación simbólica del mundo de que disponemos en nuestro habla y en nuestro pensamiento articulado. [... Mientras, los conceptos cientificos son] o bien precisiones extraordinarias de conceptos ordinarios o bien unidades simbólicas de nueva creación, establecidas por convención de la comunidad científica pertinente" (ídem).

Pasa luego a considerar, en grado mayor de generalidad y abstracción, los conceptores o conceptos teóricos los cuales son una síntesis producto de los conceptos científicos y son los que estructuran las teorías. En matemáticas tenemos p.e. que función y grupo cumplen con tal papel.

Por su lado, expresa Engels (1978) que "primero el trabajo, luego y con él la palabra articulada, fueron los dos estímulos principales bajo cuya influencia el cerebro del mono se fue transformando gradualmente en cerebro humano" (p. 10); a lo cual agrega que "el desarrollo del cerebro y de los sentidos a su servicio, la creciente claridad de conciencia, la capacidad de abstracción y de discurso, cada vez mayores, reaccionaron a su vez sobre el trabajo y la palabra, estimulando más y más su desarrollo [negrillas añadidas]” (op. cit., p. 11). Asimismo, afirma que 
gracias a la cooperación de la mano, de los órganos del lenguaje y del cerebro, no sólo cada individuo, sino también en la sociedad, los hombres fueron aprendiendo a ejecutar operaciones cada vez más complicadas, a plantearse y a alcanzar objetivos cada vez más elevados [negrillas añadidas] (op. cit., p. 15).

Estas “operaciones cada vez más complicadas" ameritaban un nivel de mayor de abstracción y condujeron paulatinamente a un proceso de matematización, el cual involucraba necesariamente el progresivo paso de los perceptos a los conceptos.

Struik (1960) expresa que

nuestras concepciones matemáticas se formaron como resultado de un prolongado proceso social e intelectual, cuyas raíces se esconden en el remoto pasado. Sus orígenes pueden buscarse en el neolítico, cuando los hombres, en lugar de limitarse a buscar y conservar alimentos, se convirtieron en productores de los mismos, sentándose los cimientos de la agricultura, la domesticación de ganado y, eventualmente, el trabajo de los metales. Los vestigios de algunas actividades de la Edad de Piedra - productos de carpintería, cestería y alfarería- prueban que esas actividades pudieron estimular el desarrollo de concepciones geométricas (p. 9).

Asimismo, "la medición está profundamente sumergida en la vida económica y comercial" (Bishop, 1999, p.58).

Lo planteado por Mosterin (1981), Engels (1978) y Struik (1960) es crucial para rebatir un sinnúmero de afirmaciones especulativas, pseudocientíficas, que circulan -y han circuladoa través de diversos medios acerca de las capacidades matemáticas de ciertas especies animales, de los niños muy pequeños o de culturas con un muy incipiente o bajo nivel tecnológico. Las capacidades matemáticas que allí podemos localizar mayormente se deben ubicar en el nivel perceptual: son perceptos y nunca se pasa a otro nivel (en los animales y en niños) y poco se desarrolla lo conceptual en los adultos de dichas culturas.

Por otra parte, nos acogemos a lo expuesto por Bishop (1999), quien expone que "las matemáticas son un fenómeno pancultural: es decir, existen en todas las culturas” (p. 37) y ubica la medición como una de las seis actividades (contar, medir, localizar, diseñar, explicar y jugar) que él considera como "universales", que "ayudan a desarrollar la tecnología simbólica que llamamos «matemáticas»" (op. cit., p. 43); vale decir, son aquellas cuyo desarrollo permite pasar de unas protomatemáticas a las matemáticas; de lo perceptual a lo conceptual.

Nos ubicamos dentro de una corriente de pensamiento que considera que el origen del conocimiento matemático, y las medidas no son una excepción, está indisolublemente 
asociado al propio origen del hombre, al proceso de hominización. Es justamente eso lo que está en la base de lo que Beyer (2016b) denomina antropomatemática.

La evolución de las diversas culturas y civilizaciones, con el consiguiente desarrollo de sus formas económicas y de las tecnologías aplicadas a los procesos productivos, ameritó un perfeccionamiento y la unificación de las medidas de un tipo determinado, una mejora en su precisión y la sistematización de los procesos de medición, todo lo cual a la postre condujo a la creación del Sistema Métrico Decimal, el cual se impuso en buena parte del globo aparejado con el desarrollo del modo de producción capitalista.

Como bien establece Kula (1980), y coinciden en ello los estudios e investigaciones,

El primer período evolutivo de las nociones metrológicas del hombre es el antropométrico, en el que las unidades básicas de las medidas son partes del cuerpo humano. El período siguiente busca sus unidades de medición en las condiciones, objetos y resultados de la labor humana.

El desarrollo del sistema metrológico y de cada una de sus partes componentes estuvo dictado, evidentemente, por las condiciones de vida y de trabajo (p. 5).

Este vínculo de las medidas con los procesos económicos y socio-políticos, con las condiciones de vida y trabajo, puede observarse desde tiempos remotos, así ya en la Biblia aparecen asuntos vinculados con la medición. Así, en diversos versículos hallamos referencias a medidas, como por ejemplo: "Ni se enciende una luz y se pone debajo de un almud, sino sobre el candelero, y alumbra a todos los que estén en casa [negrillas añadidas]" (Nuevo Testamento, Mt. 5, 15); refiriendo González Raposo (1990) que “el fraude, en el pesar y el medir, se remonta a los orígenes de la humanidad. El mecader usaba una 'balanza' para comprar: cumplida y amplia; y otra para vender: reducida y con rasero" (p. 23). Las autoridades de cada nación trataban de evitar, mediante leyes y funcionarios, los fraudes y en ello también intervenían los líderes religiosos y así se asentó en los respectivos libros sagrados: "Porque con el juicio con que juzguéis, seréis juzgados y con la medida con que medís, os será medido [negrillas añadidas]" (Mt. 7, 2).

Para afianzar algunas de las ideas antes expuestas veamos qué nos dice Kula (1980): "Desde la Alta Edad Media hasta la introducción del sistema métrico, se utilizan en Europa dos clases de medidas para las superficies agrarias: medición por el tiempo de trabajo y medición por la cantidad de granos sembrados" (p. 36). Vemos aquí una estrecha ligazón entre las medidas y la producción. 
Pero además las medidas tenían un vínculo indisoluble con los asuntos de estado como son los impositivos. Sobre esto es muy conocido el hecho de que "hace ya 6,000 años que los egipcios se veían obligados a medir las tierras del Valle del Nilo, cada vez que con sus inundaciones periódicas, al par que fertilizaban la tierra, borraba los límites de las propiedades" (Viedma, s/f., p. 5). A este efecto existían unos funcionarios, los harpedonaptas (o estiradores de cuerdas), una especie de antiguos agrimensores comisionados por el Estado para dicha labor, cuyo fin último era determinar las rentas y/o los impuestos que el propietario debía pagar. En este sentido Herodoto (citado por adurán, 2003, p. 417) expresaba:

\footnotetext{
Sesostris (el Rey), ellos dijeron, repartía las tierras de Egipto entre sus habitantes, asignándole a cada uno de ellos un terreno cuadrado del mismo tamaño obteniendo de esta manera ingresos para la renta que cada propietario debía pagarle anulmente. Si el río se llevaba parte del terreno, el propietario debía acuduír al Rey y relatarle lo que había pasado. Así, el Rey enviaría personas para examinar y determinar exactamente la dimensión de los daños causados. Luego, el propietario tenía que pagar la renta sobre el terreno que le quedaba.
}

El desarrollo de las fuerzas productivas y aparejado a ello la evolución de las ciencias y el aumento de los intercambios comerciales, producto de la expansión del comercio y de la mejora de los medios de comunicación, obligaron a que en las sociedades que tenían un mayor nivel de avance se planteara la necesidad de ir modificando los sistemas de medición y a la vez se hizo necesario el uso de un sistema de medidas común para todos . En este sentido, y como bien indica Talancón Escobedo (2006) “el sistema métrico decimal fue una invención del impulso ilustrado cuya difusión y generalización por el mundo en el siglo XIX, se convirtió en un mecanismo que facilitó los intercambios del capitalismo en expansión" (p. 24). A su vez, la ausencia de una definición clara permitía que las medidas se convirtiesen en un instrumento de dominación. Entre las ventajas que tiene dicho sistema, las cuales coadyuvaron a su difusión, están: es un sistema neutro y universal, práctico, con las unidades base reproducibles, poseedor de una nomenclatura sistemática, es decimalizado, todo lo cual lo hacía totalmente distinto y mejor a los sistemas de medición precedentes, resolviendo los inconvenientes que éstos presentaban.

La evolución de las medidas en Venezuela por supuesto no escapó a esta relación con lo económico y lo socio-político, elementos que tangencialmente irán surgiendo a lo largo de este escrito y que en parte mencionaremos en el apartado Algunos aspectos contextuales. 
A su vez, en determinado momento histórico, diferente en distintas latitudes, el asunto de las medidas entró a formar parte del conocimiento científico, y vía la Transposición Didáctica, pasó a ser uno de los contenidos del saber escolar. En consecuencia, fue incorporado a los conocimientos presentados en los textos escolares de matemáticas. Sobre éstos centraremos nuestra atención.

La Venezuela decimonónica tampoco escapó a esto último y tanto en las obras didácticas foráneas como en las nacionales podemos encontrar este tópico como parte de ellas.

En lo que sigue se explicará la evolución de las medidas en Venezuela y el tratamiento de éstas en las obras escolares de matemáticas empleadas en el país en el siglo XIX. Se mostrará el estudio y los hallazgos producidos, al hacer una revisión de un conjunto de libros elementales de matemáticas escolares (nacionales y foráneos) empleados en la Venezuela decimonónica, referidos a la evolución de la enseñanza de las medidas en el país, complementada con la información presentada en otras obras que aluden al uso de éstas, así como algunos aspectos de la legislación que rigió dicho tema en ese contexto espaciotemporal.

\section{El estudio}

El presente trabajo tiene su centro en el estudio de los textos escolares de matemáticas como fuente importante para entender la introducción y difusión del SMD en la Venezuela del siglo XIX.

Se ubica este escrito dentro de una corriente de pensamiento centrada en la historia de la educación matemática (HEM), área escasamente abordada por los inevestigadores venezolanos, y menos aún cuando se enfoca dentro del el contexto venezolano. En particular se escogió la temática del Sistema Métrico Decimal dada su importancia intrínseca y por cuanto es un tema vírgen, ya que no se han podido encontrar estudios previos al efecto desde la óptica de la HEM y sólo existen antecedes elaborados por los organismos metrológicos del país.

El estudio guarda cierta analogía con los realizados sobre la temática del SMD en otras latitudes: España (Picado Alfaro, 2012); Colombia (Arboleda, 2014); Brasil (Barreto de Brito, 2017), por sólo mencionar algunos. 
Es de hacer notar que se trata de un trabajo preliminar mediante el cual se pretende sentar las bases para un abordaje del tema con mayor profundidad, en consecuencia dejaron de abordarse ciertos aspectos resaltantes como el enfoque realizado por Arboleda (2015) aplicándolo al caso venezolano, el de la introducción del SMD asociada al proceso de la formación de la nación, en términos de sus consecuencias sociales y políticas en lo concerniente su organización y del uso de la ciencia como un instrumento de dominación por parte de una élite local, ideas que podrían asociarse con ciertos planteamientos formulados por Talancón Escobedo (2008), así como también se omitió en este estudio la consideración de obras didácticas de otras disciplinas como la teneduría de libros.

\section{Algunos elementos teóricos a considerar}

Esta investigación se encuadra dentro del campo de la historia de la educación matemática (HEM) y el objeto de estudio, el SMD dentro de los textos escolares del siglo XIX en Venezuela, es considerado en su vinculación con otros ámbitos del quehacer de la sociedad venezolana del siglo XIX.

La HEM es un campo de estudio relativamenre reciente el cual se centra en una aproximación histórica a problemas considerados dentro de la educación matemática. El interés que ha suscitado este campo puede palparse en el cúmulo de publicaciones y congresos dedicados a esta temática (Picado y Rico, 2012) y es un área de trabajo en pleno desarrollo. Dicho campo puede representarse diagramáticamente así:

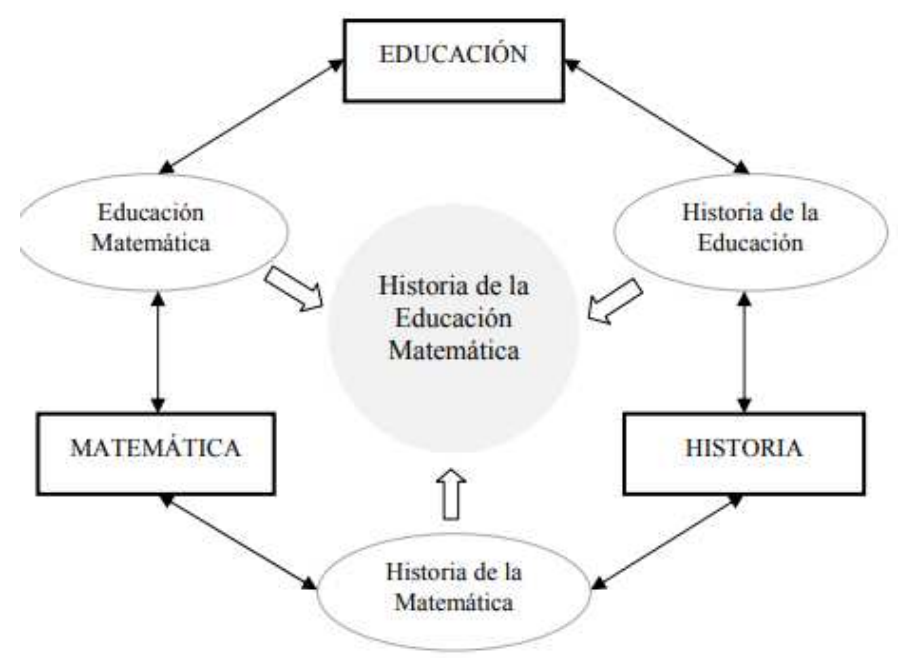

Figura 1: Relaciones de la HEM con otras áreas de conocimiento Fuente: Picado, Rico y Gómez, 2013, p. 41 
El diagrama de la Figura 1 es claro en mostrar que la HEM se encuentra en la confluencia de diversos campos disciplinares, siendo por ende un área de estudio multidisciplinario, que en buena parte se funda en aspectos teóricos tomados de esas disciplinas, así como también se nutre metodológicamente de éstas.

Dentro del campo de la HEM ha adquirido particular relevancia el estudio de textos históricos de matemáticas (Schubring, 1987; Picado y Rico, 2012).

Los textos históricos de matemáticas, como bien apunta Schubring (1987) "la práctica de la enseñanza no está tan determinada por los decretos ministeriales y por los programas de estudio oficiales como por los libros de texto usadas para ella" (p. 41).

Además, como expresan Picado y Rico (2012) “estos libros proporcionan uno de los vehículos más relevantes en los procesos de difusión y transmisión del conocimiento matemático a lo largo de la historia” (p. 11). Y justamente eso, la difusión y transmisión del conocimiento del SMD a traves de dichas fuentes escritas, es el interés central de la presente comunicación.

Sin embargo, todo esto acontece dentro de la realidad histórica en un lugar y momento específicos, en virtud de lo cual es indispensable tomar en cuenta los contextos socio-político, económico, educativo y de desarrollo de la ciencia y la tecnología, dentro de la sociedad en consideración, en ese lugar y tiempo.

Para fundamentar este trabajo, y dado que el núcleo de esta investigación se centra en los textos escolares, hemos de partir dando una conceptualización de estos objetos. En este sentido Carlós (2002) los define como

El material escrito, editado por empresas públicas o privadas y producido para ser empleado tanto por los alumnos, como docentes en las instituciones educativas sean públicas o privadas que que vuelca en su interior contenidos, ilustraciones e informaciones recogidas y seleccionadas intencionalmente, e incorpora propuestas metodológicas para el aprendizaje de acuerdo al nivel, a las políticas educativas y a los diseños curriculares vigentes (2., ๆ 1).

A esto agrega Beyer (2012) que los textos escolares

Son un producto histórico; son un producto cultural; son un componente del currículum; son un producto de la Transposición Didáctica; son un mediador entre el docente y el discente, entre la enseñanza y el aprendizaje; pero, son también una mercancía (p. 122).

Es importante señalar aquí que los textos escolares muestran un saber matemático transformado vía la Transposición Didáctica (TD): es el saber a enseñar como lo refiere 
Chevallard (2000). Ese saber el cual ciertos autores denominan matemáticas escolares difiere del saber sabio, de la matemática que hacen los matemáticos profesionales, en diferentas asprctos. Así, por ejemplo Beyer (2012) hace una comparación entre ambos saberes, caracterizándolos y diferenciándolos. Por su lado, Chervel (1991) nos habla de disciplinas escolares, especificando con el término disciplinas que

Los contenidos de la enseñanza se conciben como entidades «sui generis», propias de la clase, independientes hasta cierto punto de cualquier realidad cultural ajena a la escuela, dotadas de una organización, una economía propia y una eficacia que sólo parecen deber a sí mismas, es decir su propia historia [negrillas añadidas] (p. 63).

A lo anterior Chervel (1991) agrega: "los contenidos de la enseñanza vienen impuestos como tales a la escuela por la sociedad que la rodea y por la cultura en la que está inserta [negrillas añadidas]" (p. 64).

Lo antes citado merece algunos comentarios. La afirmación de que estos contenidos son "independientes hasta cierto punto de cualquier realidad cultural ajena a la escuela" hay que mirarla con cuidado, no sobrevaluando la supuesta independencia de tales saberes. Creemos que justamente el autor está consciente de que la afirmación puede ser mal interpretada y por ello dice que esto es "hasta cierto punto" y, además, posteriormente aclara que dichos saberes vienen en realidad impuestos a la escuela por la sociedad y cultura en la cual ésta está inserta.

Por otra parte, el primer resaltado enfatiza las características propias de dicho saber.

Adicionalmente, hay que remarcar que en nuestro caso ese proceso de TD no es autóctono sino foráneo y allí es importante la acotación realizada por Chervel (1991), la cual también hemos resaltado, en el sentido de que esos saberes los impone la sociedad. En el caso venezolano, la sociedad del siglo XIX estaba en sus inicios caracterizada por la dominación española y su cultura; luego, el país, signado por el pensamiento de los fundadores de la República, estuvo notablemente influenciado por el pensamiento ilustrado europeo; así los primeros textos matemáticos provenían del continente europeo (obras de Vallejo, Lacroix, Legendre, etc.) y luego los autóctonos se hicieron generalmente siguiendo el modelo de los importados. Las influencias más notorias fueron la hispánica y la gala, y en menor cuantía la de otra procedencia. 
Es de recalcar pues que factores "ajenos" a la realidad nacional, muchas veces, influenciaron los cambios educativos, y de otra índole, realizados en el período histórico que nos ocupa. El connotado pensador mexicano Bonfil Batalla (1991) hace un estudio detallado sobre la contraposición entre "lo propio" y "lo ajeno", refiriéndose a los objetos culturales y al control sobre los mismos.

\section{Metódica}

El ámbito de este trabajo se ubica en el contexto espacio-temporal de la Venezuela del siglo XIX.

La metodología empleada fue de tipo cualitativo, siguiendo el método histórico. Específicamente se trata de una investigación de corte histórico, de base documental y de carácter crítico-interpretativo.

Es histórica por cuanto como expresan Cohen y Manion (1990) "se ha definido la investigación histórica como la situación, evaluación y síntesis de la evidencia sistemática y objetiva con el fin de establecer hechos y extraer las conclusiones acerca de acontecimientos pasados” (p. 76), estando conscientes de que no resulta un estudio acabado en el sentido de que "la información es siempre fragmentaria y la reconstrucción proporciona un esquicio, más bien que un retrato terminado. Diferentes personas que estudian la historia de un caso pueden llegar a diferentes reconstrucciones a partir del mismo material" (Travers, 1986, p. 460).

El estudio es de base documental por cuanto se apoya en un amplio conjunto de fuentes escritas, documentos entre los que cabe destacar: textos escolares de matemáticas (nacionales y foráneos); instrumentos legales como leyes y decretos; documentos curriculares; investigaciones bibliográficas, catálogos y otras, relevantes para el tema que nos ocupa.

La investigación es de carácter crítico-interpretativo por cuanto ella no se limitó a la mera recolección, agrupamiento y ordenación de los datos; ni aún a la simple hilvanación de los estos ya agrupados y ordenados. Se fue mucho más allá, se trató de explicar los hechos o fenómenos objeto de estudio y de obtener nuevo conocimiento histórico.

Se privilegió el uso de fuentes primarias, especialmente cuando de obras didácticas y de textos jurídicos se trataba.

El origen de las fuentes fue la biblioteca personal del investigador, bibliotecas públicas como la Nacional de Venezuela y la de la Universidad Central de Venezuela, la Intenet. 
Los textos escolares considerados para el estudio son lo que Schubring (1987) denomina libros de texto históricos. Para su obtención se procedió a la revisión de catálogos de bibliotecas, como la Biblioteca Nacional de Venezuela y la Biblioteca Central de la Universidad Central de Venezuela entre otras, así como la consulta de catálogos de casas editoras del siglo XIX, en conjunto con diversos estudios bibliográficos, investigaciones sobre textos escolares y la búsqueda por Internet, permitió detectar un conjunto de obras de interés. Realizado el arqueo se procedió a extraer una lista de obras para el estudio, de la cual se extrajo una muestra intencional, muestreo en el cual, "es la persona que selecciona la muestra la que procura que esta sea representativa; por consiguiente, la representatividad depende de su intención u opinión, y la representatividad es subjetiva” (Azorín, 1972, p. 4)

La selección de las obras se hizo sobre la base de un conjunto de criterios, a saber:

1. Existencia de la obra, en papel o en versión digital

2. Presencia del tema medidas en el texto

3. Relevancia del autor

4. Permanencia en el tiempo

5. Número de ediciones

6. Referencias a su permanencia en el mercado librero

7. Indicación de algún tipo de evaluación

8. Aprobación de su uso por algún organismo oficial

9. Haber sido empleada efectivamente como texto

10. Cobertura del período en estudio

No necesariamente una obra debía satisfacer todos los criterios. Obviamente los $\mathrm{N}^{\mathrm{os}} 1$ y 2 eran obligantes, mientras que el $\mathrm{N}^{\circ} 10$ es un criterio que debía satisfacer la muestra como un todo.

Los documentos base fueron sometidos a la crítica interna y externa para garantizar la autenticidad del documento y la veracidad de su contenido. A los fines de afianzar la crítica se llevó a cabo la constrastación de diversas fuentes, cuidando que éstas -en lo posible- fuesen independientes.

Se llevó a cabo una reconstrucción histórica de la introducción del sistema métrico en el país y se consideraron elementos contextuales de diversa índole. Dentro de este marco se realizó un análisis de la información extraida de las fuentes, interpretándola, y como consecuencia se arribó a un conjunto de conclusiones.

Un aspecto a resaltar es que en las citas textuales se respeta la grafía, reglas de acentuación, etc. originales de cada autor citado. 
Finalmente, queremos indicar un aspecto limitante para trabajos de esta índole: la dificultad para la obtención de buena parte del material trascendente, esencialmente fuentes primarias. Esto es particularmente notorio cuando de textos escolares se trata, y si son antiguos más aún, resultando la mayoría de las veces imposible encontrar varias ediciones de una misma obra a fin poder determinar con certeza si entre unas y otras el autor y/o los editores realizaron cambios y de qué trataban éstos en el caso de existir. La limitación referida a los manuales escolares la explica Choppin (2000) en virtud de la poca atención que en general bibliógrafos e historiadores han puesto en ellos y en consecuencia muchas veces no son censados ni catalogados, por el tipo de uso el cual hace que su soporte físico se deteriore, a la falta de conservación de muchos catálogos de los editores, etc.

\section{Algunos aspectos contextuales}

Este estudio se ubica en la realidad política, histórica y económico-social de la Venezuela decimonónica. Constituye dicho siglo un período en el cual se produjeron diversos acontecimientos que influyeron decisivamente en el ámbito educativo y, particularmente, en la producción y difusión de las obras didácticas.

Sobre este último asunto, el de la producción y difusión de los textos escolares en el siglo XIX venezolano, existe un acucioso trabajo de investigación realizado por Beyer (2012), en el cual se resalta la influencia de los aspectos de orden contextual sobre la literatura didáctica en dicho período.

Aquí, grosso modo, expondremos sólo algunos acontecimientos y circunstancias: las más resaltantes e influyentes en el tema que nos ocupa.

El territorio de lo que hoy es Venezuela en los inicios del siglo XIX aún no era una nación, por cuanto era una colonia española y en consecuencia en la Capitanía General de Venezuela, que tal era su nombre, las medidas empleadas eran las implantadas por los colonizadores. Éstas eran hasta cierto punto suficientes para ese entonces, aunado la dependencia de la metrópoli, para el desenvolvimiento económico de la colonia.

Al pasar a ser una nueva nación, en los primeros tiempos, la marcada devastación en que sumió este territorio, como consecuencia de la cruenta guerra independentista, relegaron la necesidad de cambiar el sistema de medidas vigente; asimismo, los sucesivos enfrentamientos entre diversas facciones nacionales desviaron la atención hacia otros asuntos distintos al 
educativo y al de los aspectos de innovación técno-científica, siendo estos de los menos atendidos por los sucesivos gobiernos. Expresaba Uslar Pietri (citado por Vilda, 1997) que "pasamos el siglo XIX en puras guerras civiles, en una dispersión del poder entre jefes y jefecillos de todas clases. Páez intentó crear un Estado nacional y no pudo. Tampoco Guzmán Blanco" (p. 4). Uno de tales acontecimientos fue el desmembramiento de la "Gran Colombia", y otro, muy cruento fue la Guerra Federal (1858-1863). Buena parte de la centuria vivió el permanente enfrentamiento entre conservadores y liberales.

La economía de la época se caracterizó por "uno de los cambios económicos más significativos impulsados por la guerra nacional de Independencia [que] fue abrir el territorio venezolano al tráfico comercial internacional, de modo libre y sin las trabas vigentes en el período colonial" (Brito Figueroa, 2005, p. 225). Era una economía de base agro-pecuaria exportadora cuyo principal rubro de exportación fue el café. Además, “el predominio de Inglaterra como mercado de los productos venezolanos y como abastecedor de mercancías para satisfacer las necesidades del mercado interno, fue decisivo en este período y como tal se prolongó a todo lo largo del siglo XIX" (op. cit., p. 227).

Brito Figueroa (2005), asimismo, asevera que la estabilización económica del país, luego de la Independencia, era relativa por cuanto no hubo cambios estructurales de la economía con respecto al período anterior; tan sólo existió una apertura hacia los mercados internacionales y la dependencia de éstos, así como la necesidad de importar mercancías procesadas e incluso el numerario circulante, todo lo cual hizo que dicha economía dependiese de los avatares del capitalismo mundial, especialmente de las crisis de sobreproducción.

Esa relación que se creó con los mercados internacionales promovió la creación en el país de un cúmulo de empresas, mayormente en manos extranjeras, dedicadas a la exportación/importación de productos, y que desarrollaban una febril actividad económica en los puertos, la cual repercutía en sus respectivos hinterlands. Expone en este sentido Cardozo Galué (s/f) que

Los comerciantes extranjeros establecidos en Maracaibo, ademas de conducir el tráfico exterior y hacerse fuertes en el manejo de la plaza, acaparan para fines de la década de 1830 el comercio con las áreas productivas de Los Andes venezolanos y valles de Cúcuta (p. 16).

Este fuerte movimiento económico generaba una serie de necesidades de modernización, siendo una de ellas la actualización del sistema de pesos y medidas. 
En lo que respecta a la educación hay que decir que pocas eran las escuelas públicas existentes en el país y era un sector bastante abandonado, con falta permanente de recursos económicos y marcada escasez de maestros. En las grandes ciudades, como Caracas, hubo un marcado predominio de los planteles privados. El nivel secundario lo atendían los colegios, instituciones que vivían vicisitudes similares a las de las escuelas de primeras letras. En las universidades predominaba el escolasticismo y el uso del latín. Sin embargo, a través de ciertos personajes se colaron ciertas ideas de la Ilustración. En la de Caracas ésta dejó de ser real y pontificia gracias a su reforma, en 1827, impulsada por José María Vargas y Simón Bolívar, creándose la primera cátedra de matemáticas a nivel universitario.

En sus inicios, la educación trató de seguir el método de enseñanza mutua, siendo que incluso Lancaster estuvo un tiempo en el país.

Es de descacar que en la tercera década de la centuria fueron creadas dos instituciones importantes en el rubro educativo: La Academia de Matemáticas de Caracas, decretada en 1830 y que entró en funcionamiento en 1831, con Cagigal a la cabeza; y la Dirección General de Instrucción Pública (DGIP), en 1838, presidida por Vargas secundado por Cagigal. Ambas jugaron un importante papel en la introducción y difusión del SMD.

Se decretaron, en 1842 y 1843, los primeros instrumentos legales propios, que rigieron la educación. Posteriormente, adquirió principal relevancia para la educación primaria el Decreto de 1870, promulgado por Guzmán Blanco. Asimismo, fue creado en 1881 el Ministerio de Instrucción Pública. En esta época también la secundaria recibió renovado impulso.

Expresan Abad y otros (1984), refiriéndose que "la realidad política y educativa reflejaba que dentro de la escasa prioridad asignada a la educación, se favorecía a una educación destinada a servir a las élites en detrimento de una educación orientada al servicio del pueblo" (p. 13). Esto trató de ser revertido con el Decreto de 1870, referido a la instrucción primaria. Se caracteriza este momento por ser un intento de modernización y popularización de la educación. También data de esta época la creación de las primeras escuelas normales.

En lo referente al desarrollo de las matemáticas éste fue espasmódico. Ya en 1760 se creó la Academia de Geometría y Fortificación, institución de corta vida. Luego, en ese mismo siglo, ciertos esfuerzos desde el mundo civil, que promovían la enseñanza de las matemáticas superiores no llegaron a fructificar. Posteriormente, en el siglo XIX fueron creadas varias 
academias para la formación de ingenieros militares, de efímera existencia. No es sino hasta la creación de la Academia Matemática de Caracas que estos esfuerzos toman cuerpo.

Por otra parte, en el último cuarto del siglo XIX hubo una notoria influencia de las ideas positivistas (Spencer, Sarmiento, etc.), las cuales continuaron influyendo en la siguiente centuria, lo cual trajo como consecuencia la modernización de la ciencia y su enseñanza en el país. Ingresaron al país ideas pedagógicas como las de Pestalozzi, la enseñanza objetiva, las cuales le dieron cierto renacer a la actividad educativa.

\title{
Las medidas en Venezuela: Una visión retrospectiva
}

Como ya se dijo anteriormente, las matematicas constituyen un fenómeno pancultural y por ende los pueblos ancestrales que poblaban estas tierras, al momento de la llegada de los colonizadores, poseían dentro de sus respectivas culturas ciertos conocimientos matemáticos, cuyas huellas en muchos casos se han perdido, especialmente en las ágrafas. Sin embargo, algunos rastros (a veces deformados) aún se conservan y podemos extraer del vocabulario de los idiomas indígenas términos con connotaciones matemáticas. Así, por ejemplo, Mosonyi (2008) refiriéndose a la etnia Warao (o Guarao) establece lo siguiente:

\begin{abstract}
Ahora bien, lo que sucede realmente es que el guarao sí maneja un buen número de abstracciones, algunas de ellas muy interesantes, pero de índole totalmente distinta a las que seencuentran en las lenguas occidentales. Como veremos en seguida, se trata de conceptualizaciones enteramente originales, cuya existencia puede pasarnos desapercibida, a menos que nos propongamos la tarea de buscarlas en forma deliberada. En vez de abundar en comentarios de orden general, será preferible suministrar algunos ejemplos característicos: Sinaria y Sinarianaka: sinaria, (pronunciado sinaría), en su acepción más conocida e inmediata significa medida y sinarianaka, en una primera aproximación, sería sin medida, lo no medido o no medible (inconmensurable) (p. 154).
\end{abstract}

Este investigador acentúa el carácter polisémico del vocablo sinaria, expresando que "confrontando otros usos de ambos vocablos según resaltan de una diversidad de contextos, obtenemos para sinaria traducciones tales como 'límite', 'señal', 'molde', 'modelo', 'unidad de medida', 'hora del día (o de la noche)', 'testimonio' y otras'”, (ídem).

Este carácter polisémico de este término puede corroborarse consultando a Barral (1979):

MEDIDA. Sinaría.// 2. Medida, instrumento para medir. Sinarikoima. // 3. Medida del perímetro o contorno de la isla. Burojo a kojo a sinaría.// 4. Medida tipo, unidad de longitud, (metro, vara). Sinaría.// 5. Medida tipo de tiempo. Hora. Ya asinaría./ (SIC) Ya a kobe sinaria.//7. Tomar la medida. Kayuka (tá-). (p. 141-641). 
Por su lado, Urdaneta (1997) indica que membús era el término empleado por la etnia Cuica para significar altura y palito era una "medida de capacidad, equivalente a la mitad de un almud" (op. cit., p. 115); así como también poseían vocablos para la medición del tiempo (tshabú, tsyishbu = día, toshíta = semana, timbeu = mes). Se nota aquí ya un proceso de transculturización (o de asimilación cultural) al aceptar divisiones del tiempo como la semana y el mes o una relación con el almud, típicamente provenientes de la cultura del conquistador.

Este proceso transculturizador muchas veces viene aparejado con, o impulsado por, otros factores determinantes introducidos por una cultura dominante dentro de otra cultura. En buena medida la introducción de nuevas formas de explotación económica, así como de herramientas y artefactos producidos por una cultura de mayor desarrollo tecnológico, inducen al trasvase de instrumental matemático (mentefactos, en el sentido de D'Ambrosio (1986)) de la una a la otra. Así, por ejemplo, una

consecuencia de la mercantilización de la sarrapia en el Orinoco fue la notoria relevancia que tomó el manejo de unidades de medida, cálculos y expresiones numéricas entre las poblaciones locales. Durante la época de las estaciones sarrapieras, los mapoyo adquirieron grandes habilidades en el manejo de medidas de peso traídas por los colonos criollos (Torrealba y Scaramelli,2018, Modo de extracción y organización social, \6).

Obsérvase aquí cómo factores de índole económica guardan una estrecha vinculación con el conocimiento del proceso de medición. Manifestación clara de ello lo constituye la adscripción de los asuntos metrológicos al Ministerio de Fomento, en 1950, órgano "cuya misión básica la constituye el desarrollo y fomento de la Industria y Comercio en el país" (Colubi, 1978, p. 53).

El comercio, las instituciones educativas que fueron creándose con el paso del tiempo y, en gran medida, las obras didácticas que circularon por estos predios fueron los mecanismos que promovieron el empleo de las medidas en uso en España, las cuales perduraron, y tal es así que hasta bien entrado el siglo XX era usual que el campesino venezolano hablase en términos de arrobas, leguas, quintales y fanegas. Aún hoy en día se habla de quintales de café.

En lo que se refiere a las medidas no métricas que han sido usadas en el país, en distintos momentos históricos, se ha podido consultar el acucioso estudio realizado por Rodríguez Castillo (2000), quien entre otras cosas realiza una interesante clasificación de las mismas, basándose en criterios de carácter esencialmente económico (comercio, productos, etc.) y considerando la labor humana, siguiendo muy de cerca los planteamientos de Kula 
(1980). Así, por ejemplo, se tiene "Sistema de pesos en territorio limitado y de comercio al por menor", "Sistema de pesas de producción geográficamente diseminadas y de comercio al por mayor" o "Sistema de medidas de acuerdo al tiempo de trabajo".

Por su parte, señala Landaeta Rosales (2006) que

Desde la época de la conquista hasta el año de 1800, rigió en Venezuela el antiguo confusísimo sistema de pesas y medidas español. Este sistema fue sin embargo modificado por Real Orden de 26 de enero de 1801 y con esta modificación siguió rigiendo en Venezuela hasta el 11 de octubre de 1821 (p. 255).

La reforma española de 1801 pretendía la unificación de las medidas en el reino por cuanto en distintas regiones, bajo un mismo nombre, las respectivas medidas no coincidían. Así, por ejemplo, Dalmau Carlés (1969) reproduce las equivalencias entre las medidas antiguas que se usaban en España y las métricas, publicadas por la Dirección General del Instituto Geográfico y Estadístico de ese país, y allí se observa que la vara castellana equivalía a 0,835905 metros, mientras que la vara alicantina equivalía a 0,912 metros, la de Canarias 0,842 metros, la de Almería 0,833 metros, y así sucesivamente; así, la vara variaba su valor de una región a otra de España, cuestión ésta que heredaron sus colonias.

Sin embargo, esta reforma no logró su objetivo. "Deseando el Congreso de Colombia simplificar en lo posible tan complicado sistema, dictó en 11 de octubre de 1821 una ley sobre la materia" (Landaeta Rosales, 2006, p. 259), la cual rigió en Venezuela hasta la promulgación de una ley propia en 1857. Pero, “esta ley no llenó tampoco el objeto con que fue dictada, porque se incurrió en el error de adoptar los mismos nombres españoles para medidas muy diversas" (ídem).

Cagigal (1839a) analiza la Ley colombiana de pesas y medidas de 1821, exponiendo los defectos allí presentes, así como los existentes en la reforma de ésta efectuada en la Nueva Granada en 1836. Ambas, amén de la falta uniformidad carencían de patrones de referencia para las unidades adoptadas.

En razón de lo anterior el Secretario de lo Interior le señaló a la Legislatura, en 1831, la confusión reinante en la materia a lo largo y ancho del país, lo cual entre otras cosas, trastocaba el comercio interior. Asimismo, la Diputación Provincial de Caracas realizó en 1834 una petición a favor del SMD, alegando los grandes inconvenientes que traen aparejadas las medidas en uso para la práctica de los oficios, las operaciones mercantiles y las relaciones 
de los agricultores. En este mismo sentido se pronunció la autorizada voz del ingeniero Juan Manuel Cagigal en 1839.

Esta confusión en buena parte era heredada por cuanto, como indica Kula (1980), “en incontables casos, la unidad básica por la que se mide una extensión cultivada y la unidad básica del volumen de los áridos poseen una denominación igual o muy parecida" (p. 41). Él ejemplifica éste la situación con el caso colombiano en donde la fanega era una unidad de volumen y la fanegada lo era de superficie. Ese mismo uso de fanega y fanegada existió en Venezuela (Echeandía, 1896, 1926). Más aún, la fanega puede ser considerada tanto como una medida de superficie para tierras (medida agraria), así como una medida de capacidad o volumétrica para granos y frutos secos (medida para áridos), de acuerdo con la Ley colombiana de 1821 (Congreso General de Colombia, 1821). Mayor ambigüedad aún revistió la unidad de capacidad para líquidos llamada botella (Alvarado, 1923), la cual le trajo enormes complicaciones a Chitty para hacer sus tablas de conversión al SMD en 1868 (Landaeta Rosales, 2006).

A pesar de los intentos fallidos antes indicados para implantar el nuevo sistema de medidas, es de resaltar que Venezuela se vinculó relativamente muy temprano al Sistema Métrico Decimal. Así, el 13 de febrero de 1857 fue aprobada por el Congreso de la República la primera Ley de Pesos y Medidas de la República que derogaba el instrumento colombiano de 1821, el cual había regido hasta ese entonces, estableciendo oficialmente el uso del Sistema Métrico Decimal (SMD) en el país. Esta ley tuvo vigencia hasta 1939.

Además, es de destacar que -de acuerdo con el Portal del Sistema Autónomo Nacional de Normalización, Calidad, Metrología y Reglamentos Técnicos (SENCAMER)- Venezuela estuvo entre los primeros 10 países en adoptar el SMD; así después de Francia (1795), siguieron: Bélgica, Luxemburgo y Países Bajos, en 1816; Chile, en 1848; España, en 1849; Portugal, en 1852; Colombia, en 1853; Venezuela (13 de febrero) y México (15 de marzo), en 1857; y Venezuela fue además uno de los diecisiete países signatarios de la Convención del Metro (1875).

Asimismo, mediante el instrumento jurídico promulgado en 1857, el SMD fue introducido oficialmente en el medio educativo. En su Artículo $10^{\circ}$ establecía que "en todas las Escuelas Públicas o particulares, donde se enseña o deba enseñarse la aritmética o cualquiera otra parte de las matemáticas, es obligatoria la del sistema legal de pesas y 
medidas y su nomenclatura científica [negrillas añadidas]" (Congreso de la República, 1857a, p. 134; Congreso de la República, 1857b, p. 538). Se preveía allí que desde el $1^{\circ}$ de enero de 1858 era obligatorio su uso a nivel de los entes oficiales y a partie del $1^{\circ}$ de enero de 1859 lo sería para el resto del país.

No obstante todo lo anterior, ello fue más un desiderátum que una realidad en virtud de los acontecimientos políticos acaecidos a poco de la aprobación de la ley, particularmente la Guerra Federal (1858-1863), los cuales fueron obstáculos de peso para la aplicación de la ley, así como "su utilización y difusión fue muy lenta, por la resistencia que opusieron los distintos estratos de la sociedad venezolana" (Colubi, 1978, p. 51).

Sobre este último particular, Cagigal (1839a), un ferviente defensor de la introducción del SMD en el país, reflexionaba:

El Senado de 1837 aprobó por unanimidad un proyecto de ley, estableciendo en la República el sistema de pesas y medidas conocido con el nombre de sistema métrico; y si bien fue vivamente combatido en la Legislatura de $\mathbf{1 8 3 8}$, por algunos honorables representantes, también otros lo sostuvieron, interesando tan justas y sólidas razones, que si no llego a aprobarse, logróse al menos dejar la cuestión en pie y en disposición de poder ser discutido más adelante con pulso y detenimiento [megrillas añadidas] (p. 133).

Nótase allí las resistencias al uso del SMD en el país, en este caso presentes a nivel del órgano legislativo, aunado al hábito de usar las viejas medidas por parte de la ciudadanía, resistencias que no declinaron totalmente aún después de que fuese aprobado por ley el uso de dicho sistema.

Vencer estas resistencias fue un objetivo de diversas personalidades de la época entre las que se cuentan José Ángel Freire, Juan Manuel Cagigal y Feliciano Montenegro y Colón. En tal sentido el primero publicó un opúsculo titulado Nueva metrología, el cual estaba incorporado al $4^{\circ}$ tomo de la Geografía de Montenegro y Colón (volúmenes 3 y 4 publicados entre 1834-37), y que también se vendía por separado en la importante casa editora y librería caraqueña de Damirón y Dupouy; mientras, el segundo publicaba dos artículos acerca de la materia Cagigal (1839a, 1839b).

Una vez pasada la tempestad política de la Guerra Federal (1858-1863), se llevaron a cabo nuevas acciones para promover el uso del SMD. En el ámbito educativo es de destacar una Circular emitida en 1862, por el Ministerio de Relaciones Exteriores, a todos los gobernadores ordenándoles a que instruyeran a todos Concejos Municipales para que éstos dispusiesen la enseñanza del SMD en las escuelas primarias, públicas y privadas. Se decía que 
“al efecto los Concejos Municipales harán publicar tablas comparativas de los pesos, medidas y monedas actuales con las del sistema métrico decimal y harán que se publiquen textos elementales con ejemplos prácticos de este" (Ministerio de Relaciones Esteriores, 1862, p. 114). Entre otras acciones estuvo la adquisición por parte del Ministerio de Fomento, en 1868, de 100 ejemplares de una obra sobre SMD (Castellanos, 2017b), la cual además había sido recomendada como texto escolar. Sin duda, debió ser el escrito de Chitty (1868). También el gobierno promovió el uso del SMD, publicando ese mismo año el Arancel de derechos de importación arreglado al Sistema Métrico Decimal (Castellanos, 2017a, p. 424) y, en 1869, el folleto Ley sobre Sistema Métrici Decimal y resoluciones del Ejecutivo Provisional de la República sobre su ejecución (Castellanos, 2017b, p. 20). Asimismo, está el posterior Decreto de Instrucción Pública, Gratuita y Obligatoria promulgado por Guzmán Blanco (1870), en el cual se establece, en su Artículo $2^{\circ}$, el sistema métrico como una asignatura diferenciada, adicional a la aritmética.

A la par de la promulgación de instrumentos legales que introducían el SMD en la sociedad venezolana, diversas obras matemáticas (autóctonas y foráneas) que circularon por la geografía nacional promovieron la comprensión y uso de este sistema de pesos y medidas.

Ya entrado el siglo XX, para reimpulsar la introducción del SMD en el país, fueron emitidos un Decreto Ejecutivo en 1912 (Gómez, 1912) reiterando la obligatoriedad del empleo de las medidas métricas y una Resolución (Zumeta, 1914) reglamentando el uso del SMD, so pena de sanciones para los infractores a las normas establecidas en ambos documentos. Asimismo, se promovió la publicación y difusión de tablas de equivalencias entre las viejas y las nuevas medidas. Por otra parte, en 1939 fue sancionada una nueva Ley de Pesas y Medidas que derogaba la de 1857; como puede apreciarse la Ley de 1857 tuvo una larga vigencia: 82 años. Adicionalmente, en lo que se refiere al ámbito educativo, en 1912 comenzaron a aplicarse los primeros programas oficiales de estudio para la educación primaria (de carácter nacional y obligante) los cuales habían sido aprobados en 1911 y en los que estaba presente el estudio del SMD en los seis años de estudio (Ministerio de Instrucción Pública, 1911; Consejo de Instrucción del Distrito Federal, 1911).

Avanzando en el tiempo, en el transcurso del siglo XX y de lo que va del XXI han sido dictadas nuevas leyes sobre esta materia. Se escapa del objetivo del presente trabajo el análisis de estos instrumentos legales. 


\section{Las medidas y el papel de los libros de matemáticas en su estudio y difusión}

Como ya se ha dejado entrever, los textos de matemáticas -especialmente los escolares- jugaron un importante papel en lo referente al conocimiento de los aspectos metrológicos en Venezuela y fueron asimismo una fuente importante para la difusión e implantación del SMD en el país. Adicionalmente, concordando con Schubring (1987), los textos escolares son unos determinantes indiscutibles de la enseñanza y en consecuencia proporcionan pistas seguras para la reconstrucción del pasado escolar.

Ya hemos mencionado una obra pionera, la escrita por José Ángel Freire que por separado o adjuntada a la monumental obra de Geografía de Montenegro y Colón (así se vendía, según Cagigal, 1839b) jugó un rol de primera línea a los fines de explicar el SMD. Ambos autores estaban amparados por un bien merecido prestigio y además jugaron un importante papel en el ámbito educativo: el primero como secretario de la Dirección General de Instrucción Pública y el segundo como Director y fundador del Colegio de la Independencia (1836-1845), afamado plantel caraqueño (el segundo privado del país) que formó a un buen número de destacados venezolanos y que contaba con excelentes profesores, en cuyo plan de estudios estaba la Aritmética, el Álgebra y la Geometría. Indudablemente, la Geografía de Montenegro y Colón era texto de estudios en su colegio, y muy seguramente en buena parte de los restantes colegios privados de ese entonces. Así, este colegio y la obra de Freire fueron polos de expansión para el conocimiento del SMD. Ha de considerarse el opúsculo de Freire entre las primeras (tal vez la primera) obras dedicadas íntegramente a la explicación del SMD en el país.

No obstante ya las nociones acerca del SMD habían aparecido impresas como parte de otras obras. Una de éstas es la Aritmética de Romero y Serrano, en sus ediciones venezolanas de 1836,1840 y 1842 . Este libro es en realidad una reimpresión de la obra publicada por este autor en España en 1797 y cuya edición venezolana de 1826 constituye la primera publicación de un texto de matemáticas en Venezuela (Brito, 2002; Beyer, 2013). Un estudio pormenorizado de las distintas ediciones venezolanas de la obra se encuentra en Beyer (2013).

Al respecto, Landaeta Rosales (2006) señala:

Entendemos que las primeras tablas de conversión del "Sistema Métrico" al sistema común, que circularon en Venezuela, fueron las contenidas en un trabajo de aritmética reimpreso en Caracas, el año de $\mathbf{1 8 3 6}$ por el señor Tomás Antero, y que había sido publicado en España en años anteriores por el señor Lucas M. Romero y Serrano. 
$[\ldots]$.

A éstas siguieron las publicadas por el señor Feliciano Montenegro y Colón el año de 1837, al final del tomo $4^{\circ}$ de su Geografía general, las cuales, o son copias de las anteriores, o sus datos son tomados de la misma fuente, [...].

$[\ldots]$.

Después circularon las que trae el Tratado elemental de aritmética del señor Lacroix en su sexta edición, y que son obra del señor Rebollo y Morales. Esta edición se publicónen 1844 y la conversión de las medidas métricas es a las españolas, pues fue hecha en Madrid.

Estas tablas son iguales a las citadas anteriormente, [...].

En 1852 publicó en Valencia el señor Juan B. Montenegro un tratado de Aritmética que tiene la exposición del Sistema Métrico; pero no tablas de conversión [negrillas añadidas]. (op. cit., pp. 262-263).

Esta larga cita amerita varios comentarios. Por una parte el autor atribuye el escrito sobre SMD aparecido en la Geografía de Montenegro y Colón a éste y no a Freire, quien realmente lo elaboró; por otra parte, establece una filiación entre este escrito y la Aritmética de Romero y Serrano. Beyer (2013) asevera que la única mención a una edición de 1836 de la obra de Romero y Serrano es la que hace Landaeta Rosales. Se colige de lo expuesto por Landaeta Rosales que un problema crucial era el de la existencia de buenas tablas de conversión entre el sistema antiguo de medidas y el SMD, y viceversa. Además, hay que acotar que Rebollo Morales era un español que tradujo a Lacroix. En este breve recuento histórico se manifiesta claramente el rol de primerísima importancia que adquirieron los libros como difusores del SMD.

Con respecto al texto de Romero y Serrano (1842) éste tiene varios agregados con respecto a la edición caraqueña de 1826, indicándose en la cubierta que se trata de una edición aumentada "con las reglas de sumar, restar, multiplicar y partir fracciones decimales, y un apéndice del nuevo sistema frances en las medidas de superficie, capacidad, peso \&., con la correspondencia de las medidas y pesas inglesas con las españolas" (Romero y Serrano, 1842, Cubierta). Aparentemente esto fue realizado por el editor o por alguna persona encomendada por éste para dicha labor, y no por el autor de la obra y dicha coletilla aparece en las ediciones venezolanas (que se han podido consultar) posteriores a la de 1826.

Lo anterior indica que había un interés expreso de los editores para difundir el SMD.

Adicionalmente esta obra, de acuerdo con el estudio de Beyer (2013), fue declarada texto en varias Provincias del país. Por lo tanto, se convirtió en un importante portador del conocimiento en torno al SMD.

Por otra parte, un conjunto de obras foráneas, algunas con ediciones venezolanas jugaron un importante papel en el tema que nos ocupa. Cabe destacar aquí, además de la ya 
mencionada de Romero y Serrano, la Aritmética de Lacroix. Este libro jugó un importante papel en lo que a la introducción y difusión del SMD se refiere. Circuló en ediciones extranjeras (en francés y traducidas al castellano) y tuvo al igual que la obra de Romero y Serrano ediciones venezolanas, sirviendo además de modelo para muchos de los textos de autores autóctonos. La primera edición nacional se hizo en 1839. Un detallado estudio de la influencia de Lacroix en Venezuela aparece en Beyer (2016a), mostrando la difusión de la obra y la influencia de este autor galo en la nación suramericana.

Otros textos foráneos que influyeron notoriamente en el ámbito venezolano fueron los de Vallejo. Su Aritmética de niños era vendida en Caracas (p. e. en 1841 en el Almacén de Damirón y Dupouy, y en 1880 por la Librería Española de L. Puig Ros); mientras, su cartilla Explicación del Sistema Decimal o Métrico, aplicado a las pesas, medidas y monedas, opúsculo que complementaba a su Aritmética, cuya primera edición (1840) es anterior a la aprobación del uso de dicho sistema en España (1849), y la segunda corregida y aumentada la cual salió a la luz póstumamente en Madrid en 1852, también en alguna(s) de sus ediciones circuló por estas tierras. Esta temática la introdujo Vallejo en su Tratado elemental de Matemáticas. A su vez, el SMD aparece incorporado como un apéndice en la $5^{\mathrm{a}}$ edición del Compendio de matemáticas puras y mixtas, publicada por sus herederos en 1855, obra que era vendida ese mismo año por la Imprenta y Librería de Carreño Hermanos y, en 1880, por la Librería Española de L. Puig Ros.

Asimismo, lugar relevante ocupa el libro de Sarmiento sobre sistema métrico publicado en 1860 el cual influyó notoriamente sobre el autor venezolano Gualterio Chitty, aspecto que será tratado en el siguiente apartado.

Sobre la obra de Juan Butista Montenegro cabe citar lo expuesto sobre ella en el Catálogo realizado por Villegas (1974):

Elementos de Aritmética Teórica y Práctica por Juan Bautista Montenegro. Deseoso el autor de que sus "elementos" fueran efectivamente provechosos á los niños que concurren á las escuelas, los extractó con mucha habilidad de Lacroix y otros autores, y los cuadros de _veruter y Lamotte. Fueron publicados en Valencia, en 1844, se han hecho diez ediciones de ellos, y sirven de texto en varios planteles (p. 60).

Así, la presencia del tema de las medidas en las obras de matemáticas, principalmente en las de aritmética y la aparición de libros dedicados específicamente al tratamiento del SMD, fue un hecho de trascendental importancia y contribuyó decididamente a la 
implantación del SMD en Venezuela. Esto será tratado con más detalle en el siguiente apartado.

\section{Las medidas en los libros escolares de aritmética}

La revisión de diversos textos de matemáticas que circularon por Venezuela, durante el siglo XIX, permite afirmar que en las dedicadas a la aritmética el estudio de las medidas era un tema obligatorio. A ello contribuía el hecho de que dichos libros contenían muchos contenidos y ejemplos referidos a la aritmética comercial o mercantil, en donde de manera natural era necesario el empleo de medidas. Esto ha podido constatarse desde las primeras obras nacionales de su tipo como la de Chiquito (1842) y la de Echeandía (1843).

En el libro de Chiquito (1842) el tratamiento de las medidas forma parte del Capítulo IV denominado De las aplicaciones usuales de la aritmética. Dicho tema se presenta vía un conjunto de tablas, comenzando con las medidas monetarias y las temporales. Posteriormente, se pasa a considerar las de longitud y las de capacidad (diferenciando las usadas para líquidos de las empleadas para áridos), cerrando con las ponderales. A los fines explicativos expone el modo de empleo o funcionamiento de la última tabla. El autor ni siquiera asoma el SMD, el cual debió serle conocido a través de la Aritmética de Lacroix que evidentemente consultó.

En lo que concierne a Echeandía, para el año 1874 ya habían salido de la imprenta nueve ediciones de su texto.

Hay que destacar que la obra de Echeandía siguió editándose hasta entrado el siglo $\mathrm{XX}$; pero, sus editores quienes siguieron publicando el libro muchos años después de la muerte del autor, no se decidieron por incorporar plenamente el SMD y dejaron que éste coexistiera con el sistema antiguo. Mediante el método catequístico se exponen allí nociones acerca del SMD; se presentan reducciones del sistema antiguo al métrico y viceversa, existiendo en la obra una tabla de equivalencias entre ambos sistemas, así como de las métricas a las medidas de otros países; finalmente se pasa a considerar lo que él denomina “medidas corrientes en Venezuela" (Echeandía, 1896, 1926).

El prolongado tiempo que estuvo en uso este libro habla a las claras de la influencia que pudo haber tenido, básicamente en el medio educativo.

Otra obra de ese tiempo lo constituye la de Juan Bautista Montenegro, cuya primera edición data de 1844, a la cual ya hicimos referencia con anterioridad. Notoria también por sus 
reediciones y por incorporar el SMD, por lo menos desde la de 1852, según indica Landaeta Rosales (2006), aunque sin tablas de conversión.

Diversos libros salieron a la luz alrededor de mediados del siglo XIX. Así, por ejemplo, tenemos la obra Tratado de aritmética elemental de Manuel Piñero Olivero, la cual de acuerdo con Villegas (1974) fue publicado inicialmente en Valencia en 1850. La quinta salió a la luz en 1884 y la sexta en 1896 ó 1897 (el ejemplar revisado tenía dos portadas, una con un año y la otra con otro). En 1852 también Eduardo Ochoa publica en Caracas una obra que, de acuerdo con Landaeta Rosales (2006) contenía tablas del SMD, aunque él manifiesta no haber consultado el libro, sino sólo haber tenido noticias del mismo. Este texto es reseñado por Villegas (1974), pero éste no hace mención alguna a los contenidos. Por su lado, Alejandro Ibarra publica su Compendio de Aritmética Teórica y Práctica, obra publicada en dos partes:una, la teórica en 1855 y la otra, la práctica, en 1860. Se tiene la obra de Ramón Isidro Montes que data de 1856.

Diversas obras de aritmética publicadas mediado el siglo XIX siguieron reeditánse, algunas con cambios y adiciones y otras sin ello.

La obra del Presbítero Piñero Olivero (¿1896?/¿1897?) corresponde a la $6^{\text {a }}$ edición de una de las que fue reeditándose. Como antes se indicó, apareció inicialmente justo a la mitad de la centuria: en 1850. Villegas (1974) comenta sobre el texto que éste "contiene todo lo concerniente a la aritmética comercial" (p. 60). La obra incluye un escrito denominado Juicio de la obra, firmado por cuatro connotados personajes, y en el cual se asientan expresiones laudatorias acerca del texto, en particular acerca de la exposición del tema referido al SMD. Este tópico ocupa un capítulo completo del impreso, así como dedica también uno a los tópicos de aritmética comercial.

El Compendio de aritmética práctica para las escuelas primarias de Ramón Isidro Montes (Montes, 1896) es un libro cuya larga permanencia en el mercado de textos escolares, aunada a la notoriedad de su autor, se convirtieron en las razones que produjeron su gran influencia en el ámbito educativo. El Privilegio de la obra fue otorgado en Caracas y está fechado en 1856, año en el cual -según Villegas (1974)- salió la $1^{a}$ edición, publicada en Ciudad Bolívar.

La edición consultada fue la de 1873 (la $6^{\mathrm{a}}$ ), la cual se señala como aumentada y corregida. Asimismo, allí se hace mención a una $2^{\mathrm{a}}$ edición (1862) y a una $3^{\mathrm{a}}$ (1866); mientras 
que Sánchez (1946) cataloga una edición de 1896, siendo pues tanto el número de ediciones y la perdurabilidad del libro, así como la proximidad temporal entre las ediciones indicios claros de la demanda y éxito del texto. Seguramente incidió también en ello notablemente el prestigio de la Academia de Matemáticas de Caracas, de la cual era egresado el autor con el título de ingeniero, así como el hecho de que la obra fue evaluada por esta corporación, teniendo un informe laudatorio que se incorporó dentro del libro y adicionalmente hubo un Resuelto de 1856 mediante el cual se le declara texto recomendado para la enseñanza en las escuelas primarias del país. Ya en la Portada se indicaba: "Texto adoptado para las escuelas del antiguo colejio de Santo Tomás, hoy en el Colejio de Santa María, en el colejio de instrucción elemental y mercantil, y en varios otros colejios y escuelas públicas y particulares de esta capital" (Montes, 1873, Portada).

Es de anotar aquí que la denominación colegio, para la época, se refería a una institución de educación secundaria, que podía también ofrecer adicionalmente enseñanza primaria. Además, Santo Tomás y Santa María hacen referencia a instituciones privadas.

El tema de las medidas lo inicia con el sistema antiguo, empezando por las monedas y luego pasa a longitudes, capacidades y pesos, proporcionando unidades mayores y menores contenidas en las primeras, estableciendo las correspondientes relaciones numéricas entre las de mayor orden y las de menor orden de una misma especie. Posteriormente entra a considerar el SMD, del cual es buen conocedor por su formación profesional. En los ejercicios/problemas el autor sigue empleando el sistema antiguo de medidas, aunque en el texto presenta el SMD, lo cual es explicable ya que la primera edición (1856) es previa a la Ley que acoge al SMD (1857).

Ibarra (1860) toca el tema de las medidas al inicio de la segunda parte de su libro. Lo aborda iniciando con las medidas antiguas en uso, haciendo alusión a la Real Orden de 1801 que unificaba las medidas en España y a la Ley colombiana de 1821. Sigue mostrando algunos cuadros que permiten ver la relación entre unidades y subunidades de una especie, para finalizar exponiendo el SMD. El autor no muestra conversiones entre uno y otro sistema.

En muchos libros publicados hacia finales de la centuria (esencialmente los de aritmética), así como en reediciones de los existentes, se mantiene la mayoría de ellos a dos aguas: dejan coexistir al sistema de medidas antiguo con el SMD. 
En Coronado Millán (1882) se da el caso de coexistencia de ambos sistemas, pero aún mantiene allí mucho peso el sistema antiguo de medidas, pensamos que ello se deba un poco para rendirle tributo a la tradición y además por razones de orden práctico por cuanto el SMD aún no estaba instalado en el día a día de los venezolanos y ello -entre otras cosas- podía disminuir el número de los potenciales compradores de la obra. El autor, a medida que expone, proporciona equivalencias entre los dos sistemas.

Este entrecruzamiente es a veces confuso. Así, por emplo, expone

De líquidos

La carga que tiene 80 ó 100 botellas.

La botella que tiene 70 centilitros justos (p. 25).

$\mathrm{Ni}$ la carga ni la botella son medidas métricas, pertenecen al sistema antiguo; mientras que el centilitro sí se corresponde con el SMD. Más aún, la botella era justamente una de las medidas más ambiguas que tenía el sistema antiguo, dificultad con la que tropezó Chitty en su trabajo de 1868 y logró resolver obteniendo justamente el resultado mostrado por Coronado Millán, quien seguramente lo tomo de esa fuente.

El autor está muy consciente de lo no idóneo de las medidas antiguas por cuanto, al inicio de su exposición sobre este tópico, expresa: "Inmensa y por demas confusa es la variedad de las medidas que se usaban antiguamente; pero por fortuna van desapareciendo á la influencia del sistema decimal" (ídem).

En la obra de fines de siglo de Crespo (1893) aún se insiste mucho en explicar las medidas antiguas, presentando tablas de éstas con indicación de submúltiplos de ellas. No obstante el autor presenta el SMD y muestra la relación de las principales unidades de las medidas y pesas antiguas de Venezuela con respecto a las métricas. También coloca una nota en la cual asienta: "El maestro procurará que los alumnos se ejerciten mucho en la reducción de pesas y medidas métricas á antiguas venezolanas” (op. cit., p.116). Posteriormente, en otra nota propone: "Debe procurar el maestro que sus discípulos se ejerciten en la conversión de pesas y medidas antiguas venezolanas á kas métricas” (op. cit., p. 117).

El ejemplar consultado corresponde a la $4^{\text {a }}$ edición. Sin embargo, el Privilegio dado en Maracaibo esta fechado en 1855. El autor dedica la obra a José Ignacio Paz Castillo, fundador del Colegio La Paz. Además, se manifiesta que "esta obra fue adoptada como Texto de enseñanza en las provincias de Maracaibo, Coro, Mérida, Trujillo y Táchira. La primera es hoy el Estado ZULIA; la segunda el Estado FALCÓN, y las tres últimas forman el Estado Los 
Andes" (p. s/n). Esto muestra la cobertura del libro, sumado a que del mismo se hicieron diversas ediciones Villegas (1974) indica que la 3 $3^{a}$ se hizo en San Cristóbal en 1867.

En las postrimerías del siglo XIX, específicamente en 1895, se publicó la primera edición del Tratado de Aritmética esencialmente práctica y nociones sobre el sistema métrico decimal, cuyo autor es el agrimensor e ingeniero Marcos Landáez.

Es importante la mención expresa del SMD en el título de la obra y el hecho de que la misma indica en su carátula que es un "texto adoptado por la «Escuela La Verdad» y para las escuelas primarias de la República". Asimismo, contiene una Resolución fechada en 1894 y firmada por Luis Ezpelosin, a la sazón Ministro de Instrucción Pública, en la cual se asienta que el libro ha sido declarado como uno de los textos para la enseñanza primaria en el país. En la Advertencia, el autor justifa la introducción del SMD. A este respecto escribe:

\begin{abstract}
Al final de la parte de este libro dedicada á la Aritmética, damos un compendio lo más explicado posible, del Sistema Métrico Decimal. Materia esta cuyo aprendizaje es de grandísima importancia, ya por ser el sistema adoptado oficialmente en Venezuela, ya por la facilidad que ofrece para los cálculos, ya en fin, por estar tan generalizado que aun los países más refractarios á su adopción, ó lo han aceptado ya ó están en vía de aceptarlo (Landáez, 1895, p. 8).
\end{abstract}

En la $2^{\mathrm{a}}$ edición de 1910 se repite el mismo pensamiento.

No obstante lo antes expuesto, el autor no elude la presentación de las antiguas medidas las cuales estaban aún en uso por buena parte de la población, incluidos los pequeños comerciantes interioranos. Así, encontramos todavía en la $2^{\text {a }}$ edición ejercicios (éste está expuesto bajo la denominación de "Problema") como el que sigue, en donde se usan unidades (monetarias y de longitud) antiguas:

$1^{\circ}$ Compré 1538 varas de cinta, á 18 centavos la vara: ¿cuántos reales debo pagar? (Landáez, 1910, p. 38).

Es interesante observar la aparición de unidades de medida asociadas a un bien específico. Un ejemplo de ello es el de la carga de papelón la cual, en una nota al pie (Landáez, 1895, p. 30; Landáez, 1910, p. 38), se especifica que "tiene 64 papelones".

En la $1^{a}$ edición encontramos que hace uso abundante de las medidas antiguas. Así, por ejemplo en la sección Problemas de división (Landáez, 1895, p. 50) las unidades empleadas son las del viejo sistema metrológico. Igual sucede con la sección subsiguiente (Problemas misceláneos).

En la segunda edición (Landáez, 1910), el tópico SMD es cubierto mediante los siguientes contenidos: Descripción del SMD; tipos de medidas; medidas de longitud, 
superficie, volumen, capacidad y peso; definición de cuadrado, de ángulo recto, de cubo; múltiplos y submúltiplos de las medidas; $\mathrm{y}$, sistema monetario venezolano. Esto diferencia a esta edición de la anterior. En la primera él proporciona tablas de equivalencias entre ambos sistemas y entre distintos tipos de monedas (Landáez, 1895, pp. 62-65), las cuales quedan intercaladas entre los contenidos de las secciones referidas a División de decimales (pp. 59-61) y Quebrados (pp. 65-72). Luego el tema de las medidas es retomado en la sección Denominados referida a números denominados o complejos y por supuesto allí en los ejemplos aparecen nuevamente las medidas antiguas. Obsérvase pues que los contenidos de SMD parecen entreverados con otros En la $2^{\mathrm{a}}$ edición es más plena la incorporación del SMD, a diferencia de lo que acontece con la $1^{\text {a }}$ edición, en donde sólo hay atisbos del mismo.

La declaratoria del Ministro aunada a la formación y prestigio del autor hacen presuponer que dicho texto tuvo que ejercer una notable influencia para difundir el SMD en el país. En la $2^{a}$ edición (la de 1910) se advierte que es una edición aumentada y corregida y de la revisión y comparación efectuada a ambas, quedó claro que la exposición del SMD cambió con respecto a la edición de 1895, ampliándose notablemente.

Para la conclusión del siglo puede decirse que el SMD ya está bastante instaurado en las obras didácticas, aunque no por ello dejen de presentarse eventualmente actividades que involucren medidas antiguas, lo cual es explicable en vista de que en la vidacotidiana aún prevalecía el uso del antiguo sistema metrológico.

Tomemos por caso la Aritmética Práctica de Miguel Páez Pumar, editada en 1900. Este autor le dedica un capítulo completo al tema, el cuarto.

El enunciado del Ejercicio 104 de la obra es: "Un mercader ha comprado 138 quintales de café á $\$ 17$ quintal; vendió 79 á \$23, y ganó en el resto \$148: ¿Cuánto ha ganado por todo?” (Páez Pumar, 1900, pp. 41-42). Vemos que aquí usa medidas antiguas, incluso la monetaria (pesos); sin embargo, es de acotar que aún hoy en día el quintal sigue vigente en el comercio cafetero. Otros enunciados los sitúa en la realidad del momento, involucrando trenes y empleando medidas modernas (Km, Km/h, etc.).

El autor ostentaba el título de Dr. en Ciencias (equivalente a Ingeniero), lo que indica que era un conocedor profundo de la temática. Asimismo, fundó el Colegio Agustín Aveledo y la Librería Moderna. 
Al igual que otros textos ya comentados, éste fue empleado en diversos colegios lo cual se indica en la Portada: Santa María, Agustín Aveledo, San Agustín, San Vicente de Paúl, San José de Tarbes, todos ellos planteles privados sitos en Caracas; además estaban el Cajigal ubicado en Valencia y fuera de las fronteras patrias el Baralt, en Curaçao. Lo anterior permite considerar la influencia que tal libro tuvo en su momento.

Otras obras a ser mencionadas son los textos escritos expresamente para la enseñanza de la aritmética comercial o mercantil, rama dentro de la cual se emplean profusamente las medidas. En este sentido cabe destacar dos obras en particular: Aritmética para el uso de las escuelas de Venezuela (Malo, 1847) y Aritmética comercial de reglas breves para todos los cálculos que se efectúan con los números (Iradi, 1874). Evidentemente, por la época de su publicación, la primera de las obras usa exclusivamente medidas antiguas y las tablas mostradas se refieren solamente a conversiones que las involucren. Por su parte, en la segunda es apenas en la página 19 cuando se menciona una unidad métrica y luego en las páginas $20 \mathrm{y}$ 45. La obra emplea esencialmente medidas monetarias y en los pocos casos en que requiere otro tipo de medidas emplea las antiguas. Como estas obras tienen una orientación hacia el uso práctico, el de la actividad comercial, es de observar que para 1874 estaba muy instalado en la sociedad venezolana el viejo sistema de medidas. Un estudio comparativo entre ambas obras lo realizó Beyer (2017).

Vale la pena acotar aquí un punto importante referido a la enseñanza de los sistemas de medidas. La exposición del sistema de medidas antiguo imponía necesariamente el tratamiento de los números complejos o denominados. A diferencia de ello, la exposición del SMD amerita sólo el estudio de las fracciones decimales. Así, en muchas de las obras se encuentra el estudio de ambos (denominados y decimales). El estudio de los números denominados implicaba una enorme inversión de tiempo y el aprendizaje de un buen número de equivalencias entre unidades de distinto orden: p. e. conocer que en el peso para especies, mercancías y metales (salvo el oro y la plata), 36 granos hacen 1 adarme; 16 adarmes 1 onza; 16 onzas 1 libra; 25 libras 1 arroba; 4 arrobas 1 quintal (Malo, 1847). Pero, en las medidas para áridos se tiene que 4 ochavillos hacen 1 ochavo; 4 ochavos 1 cuartillo; 4 cuartillos 1 celemín o almud; 12 almudes 1 fanega; 12 fanegas 1 cahiz (ídem). Puede apreciarse que no existe ninguna regla o sistematicidad en las subdivisiones y, en consecuencia, la única forma de aprendizaje consistiría en la memorización. Toda esta complejidad se evita dentro del SMD 
donde siempre nos movemos de 10 en 10. Debía pues, enseñarse las cuatro operaciones básicas para tales números. Adicionalmente el asunto se complicaba por el hecho de que había medidas de capacidad para líquidos y unas diferentes para áridos; así como no existía un valor uniforme para una misma medida. Sobre esto último es ilustrativo el siguiente ejemplo: Expone Alvarado (1923) que la carga de papelón varía en extremo, siendo en Barcelona 80 piezas (200 libras), en Coro 40 piezas (140 libras), en Guanare 160 piezas (240 libras), es decir que varía tanto el número de piezas como el peso de cada una.

\section{Las medidas en los libros que tratan exclusivamente el SMD}

Las obras que dan un vuelco a la situación son aquellas dedicadas única y exclusivamente a la exposición del SMD. Éstas empezaron a surgir relativamente temprano, como la ya mencionada de Freire (1837).

Existen referencias a diversas obras didácticas sobre el tema. Así, el destacado educador tachirense Juan de Dios Bustamante Rosales publicó en San Cristóbal, en 1873, sus Lecciones de Sistema Métrico Decimal. Otra de tales obras es Lecciones de Sistema Métrico, publicado en 1883, en Valencia, por el Dr. Gonzalo Fajardo quien era profesor del Colegio Ramírez de dicha ciudad.

El timón del asunto fue tomado por varios egresados de la Academia de Matemáticas, titulados como ingenieros por dicha corporación: Francisco de Paula Acosta y Florencio Oviedo; Gualterio Chitty; Jesús Muñoz Tébar.

Trataron estos autores de llenar el vacío denunciado por Landaeta Rosales (2006): "Uno de los inconvenientes que se presentaban para poner en ejecución la ley de 1857, era la falta de unas tablas de conversión que tuviesen toda la precisión y claridad que se requería" ( $p$. 266).

Este tema, el de las tablas de conversión, fue abordado por Francisco de Paula Acosta y Florencio Oviedo. Estos ingenieros eran egresados de la Academia de Matemáticas y el primero incluso fue docente en dicho plantel. Ellos elaboraron una de las primeras obras dedicadas a la metrología: Explicación del Sistema Métrico Decimal. Acompañada de tablas para la correspondencia entre las nuevas y las viejas medidas, libro que fue impreso en Caracas en 1862.

No se ha podido acceder a la importante obra escrita por estos destacados ingenieros. 
Informa Landaeta Rosales (2006) que

En los números 3 y 4 de la Revista Científica del Colegio de Ingenieros de Venezuela, correspondientes al 5 y 20 de febrero de 1862, publicó el mismo doctor Francisco de Paula Acosta, dos artículos sobre metrología en uno de los cuales establece las bases para unas tablas de conversión del Sistema Métrico al coún (pp. 265-266).

Sin embargo, las tablas elaboradas por estos autores contienen ciertas imprecisiones, según expone Landaeta Rosales (2006).

Una mención muy especial merece la obra de Gualterio Chitty. Se trata de impreso que lleva por título Sistema métrico. Exposición completa, teórica i sobre todo práctica de este sistema, con tablas para las reducciones de las antiguas pesas $i$ medidas a las nuevas $y$ viceversa. Destinado especialmente al comercio $i$ a las escuelas de los Estados Unidos de Venezuela (Chitty, 1868). Como puede apreciarse desde el mismo título de la obra el escrito tenía por destinatarios dos ámbitos disímiles: el del comercio y el escolar. Puede notarse aquí claramente el estrecho nexo del tema con la realidad económica y socio-política del momento: el desarrollo de la economía había alcanzado un nivel que requería el empleo de un sistema de medidas más preciso, uniforme, sin las inconsistencias que presentaba el sistema antiguo de medidas y ello ameritaba poder aplicarlo en la práctica diaria, lo cual hacía indispensable la construcción de unas buenas tablas que relacionaran el viejo y el nuevo sistema.

La guía de Chitty para la ejecución de esta tarea fue sin duda, y así lo manifiesta él mismo, la obra de Domingo Faustino Sarmiento. Incluso, aclara el autor seguir la ortografía que emplea el argentino. La deuda intelectual con Sarmiento la expone señalando que

Entre las muchas obras que tratan de la materia no podríamos acertar mejor que escojiendo para la base de nuestros trabajos la publicada por órden del señor Domingo F. Sarmiento, Ministro de Gobierno de Buenos Aires, i sobre la cual está calcada, por decirlo así, esta noticia (Chitty, 1868, Advertencia, p. s/n).

Con respecto a la obra argentina es de anotar, como acotación al margen, que en realidad ésta es de la autoría de Sarmiento, de acuerdo con una investigación que hemos realizado, la cual aún no está publicada, aseveración para la cual tenemos sólidos argumentos a pesar de que en comunicaciones sostenidas con diversos entes y estudiosos de la nación austral éstos no aceptan esta posibilidad, amparándose en que dicho escrito no aparece en las Obras Completas (que en realidad no son tales) de Sarmiento. Sin embargo, no es éste el lugar para ahondar sobre el tema el cual se escapa a los objetivos del presente trabajo. 
El escrito de Chitty está estructurado en cuatro capítulos, a saber:

I. Noticia sobre el sistema métrico

II. Pesos y medidas de Venezuela, con los correspondientes pesos y medidas métricos.

III. Ventajas del sistema métrico

IV. Conversión de las antiguas pesas y medidas a las nuevas y recíprocamente.

Sobre esta obra Landaeta Rosales (2006) expresa que "fue examinada por varias comisiones nombradas al efecto, y no habiéndosele encontrado ningúnerror, el Gobierno dispuso se enseñase por ella en todas las escuelas, y que sus cálculos se tuviesen como oficiales en las oficinas de Hacienda y contabilidad" (p. 268). Es decir, Chitty llenó el vacío existente referido a las tablas de conversión y ese fue su gran aporte. Parte de la obra, lo referido a las noticias acerca del SMD y sus ventajas las calcó de Sarmiento.

Uno de los aspectos más difíciles del asunto, al cual se enfrentó Chitty, era determinar el equivalente métrico de la botella; sin embargo, logró superar este escollo.

Una obra posterior se debe a Jesús Muñoz Tébar (1847-1909) quien publicó en 1873, en Caracas, su Catecismo del Sistema Métrico Decimal para uso de las escuelas de la República. De acuerdo con Sánchez (1946), en 1889, en Puerto Cabello, salía la $5^{\text {a }}$ edición y en 1910 (póstumamente) la $6^{\mathrm{a}}$ en Caracas. Sin embargo, tenemos a la mano una $5^{\mathrm{a}}$ edición fechada 1897. Posiblemente ésta se trate de una reimpresión de la de 1889. Beyer (2012) menciona la edición $11^{\mathrm{a}}$ de 1832 .

En su catálogo de 1905 la Librería Española, refiriéndose a este texto, resalta que "este libro está adoptado como texto de enseñanza en los principales colegios de Venezuela" (Librería Española, 1905, p. 39). Asimismo, la obra ya la ofrecía esta empresa en su catálogo de 1884 y en el de Rojas Hermanos de ese mismo año aparecía a la venta, especificando en éste que se trataba de la $4^{\mathrm{a}}$ edición. Esta última casa editorial lo anunciaba como edición propia en su catálogo de 1874 (evidentemente se trataba de la $1^{\text {a }}$ edición). En la edición consultada (Muñoz Tébar, 1897) hay una "Advertencia de los editores en la segunda edición" fechada en 1875 y firmada por Rojas Hermanos.

En la Advertencia antes mencionada se asienta que

En menos de dos años se ha agotado la primera edición [..., y aceptado desde su aparición como texto de enseñanza en todos los colegios y escuelas de la República [...], su autor ha querido ensancharlo en una segunda edición, modificando el método expositivo y aclarando todo aquello que contribuya á la comprensibilidad de la doctrina y á los resultados de la práctica (Rojas Hermanos, 1875, p. 5). 
El texto lleva la denominación de catecismo, y como su nombre lo indica, esa ha debido ser la presentación del mismo en su primera edición. La que tenemos a la mano (la de 1897) ya no es un catecismo: ha sido modificado el método de presentación de los contenidos. Ha eso seguamente se refieren los editores cuando expresan que el autor modificó el método expositivo. La presencia de un cuestionario asociado directamente con la exposición hace que Beyer (2012) la clasifique como un cuasi-catecismo.

Como puede apreciarse, la obra sufrió cambios a lo largo del tiempo, en principio realizados por su autor. Eventualmente pudiera haber habido modificaciones posteriores, aunque en este caso serían atribuibles a los editores, por cuanto el autor falleció en 1909 y la obra siguió editándose póstumamente.

El autor fue un personaje muy importante para la época, ostentando el cargo de ministro en varios despachos del ejecutivo, fue rector de la Universidad Central de Venezuela, ingeniero activo, docente, director de una escuela pública experimental, Director de Instrucción Primaria, entre otras cosas. Su libro propagó enormemente el SMD en virtud de la extensión temporal de su uso, del peso intelectual del autor y de la influencia ejercida por Muñoz Tébar en distintos ámbitos de la sociedad.

La estructura de la obra es

I. Nociones Preliminares

II. Medidas delongitud

III. Medidas de superficie

IV. Medidas de volumen y de capacidad

V. Medidas de peso

VI. Sistema monetario

VII. Forma y dimensiones de algunas medidas

VIII. Errores tolerables en las pesas y medidas

IX. Operaciones aritméticas

Repaso

Tablas

Ejercicios

Problemas

Conversión de monedas

Apéndice

El cuerpo del texto lo conforman los nueve capítulos o apartados numerados, el resto son una especie de anexos o complementos.

Puede aseverarse que, amén del sentido evidente propagandístico de los primeros editores -Rojas Hermanos-, su afirmación del extenso uso del texto es cierta, pues esto se 
corrobora por su aceptación durante un largo período de tiempo, lo cual ameritó la multiplicidad de ediciones que tuvo, algunas agotadas rápidamente.

Ya con anterioridad se había venido advirtiendo que uno de los principales escolloes para la aplicación práctica del SMD consistíe en la necesidad de poseer adecuadas tablas de converción entre las viejas medidas y las modernas. En ese sentido diversas personas se dedicaron a subsanar esta carencia. Uno de los trabajos realizados en pro de esto fue el de Alfredo Pacheco, quien publicó en 1894 un folleto denominado Guía práctica de reducciones de monedas y otras medidas al alcance de los niños (Pacheco, 1894).

Como su nombre lo indica, el énfasis está puesto en la conversión entre distintos tipos de moneda y, en segundo plano, se dedica a realizar conversiones entre el sistema antiguo de medidas y el SMD, considerando las medidas lineales, las de capacidad, las de peso; así como también aborda la conversión entre diferentes medidas del sistema antiguo (unidades superiores a inferiores y viceversa) y además estudia las medidas de tiempo.

La exposición que realiza el autor es un claro indicativo que para ese entonces el sistema antiguo de medidas tenía aún plena vigencia en la práctica, en la vida cotidiana. Asimismo, a pesar de que el folleto en su título señala a los niños como destinatarios de la obra se hace evidente su utilidad para los comerciantes.

\section{Algunas conclusiones relevantes}

De seguidas se indican las princcipales conclusiones a las que codujo la indagación:

- La necesidad de introducir el SMD en el país surgió como una consecuencia del desarrollo alcanzado por las necesidades locales del comercio y el papel del país dentro del ámbito de la expansión en el orbe del modo de producción capitalista.

- La introducción del SMD en Venezuela estuvo expuesta a muchas resistencias por distintos sectores de la sociedad. Asimismo, los avatares políticos fueron un factor retardatario en la aplicación del sistema una vez aprobado legalmente su uso en 1857.

- Un papel de primerísima importancia en el proceso de incorporación del SMD, a la sociedad en general y al ámbito escolar en particular, lo tuvieron dos instituciones: la Dirección General de Instrucción Pública 
(creada en 1838) y la Academia de Matemáticas de Caracas (creada en 1830); la primera mandando a evaluar ciertas obras (proceso generalmente realizado por la Academia) y decretando el uso en las escuelas y colegios de aquellas aprobadas. La segunda evaluando obras mediante comisiones nombradas en su seno y por medio de la redacción de obras de aritmética y sistema métrico por parte de varios de sus ilustres egresados, así como la participación de varios de sus docentes y egresados (comenzando por Cagigal), en diversas instancias (incluída la legislatura), en las discusiones que conllevaron a la aprobación por ley del uso del SMD en el país.

- La Ley de 1857, Decretos como el de Guzmán Blanco en 1870 y otros instrumentos legales obligaban al uso del SMD dentro del ámbito escolar.

- $\quad$ El estudio del SMD fue incorporado al currículo, en buena parte mediante el uso de las obras escolares. En el plan de estudios el SMD a veces formaba parte de los contenidos de aritmética y en otras oportunidades era un tema relativamente independiente.

- Los textos escolares, escritos por autores nacionales, fueron un factor determinante en la implantación del SMD en el país. Los textos iniciales eran obras de aritmética que incluían el SMD, pero luego surgieron libros específicos sobre el tema. Entre éstos últimos destacaron los escritos de Chitty (1868) y Muñoz Tébar (1897).

- Un conjunto de obras extranjeras, algunas editadas en el país, cumplieron un notorio papel en la implantación y difusión del SMD en Venezuela. Entre éstas resaltan las de Romero y Serrano, Lacroix, Vallejo y Sarmiento.

- Los textos escolares son un producto de la TD, pero en los seleccionados ésta se realizó básicamente en otras latitudes, siendo poco el aporte autóctono a este proceso, deviniendo en consecuencia -por la servidumbre a ideas foráneas- a ser un producto cultural ajeno. Incluso ello es notorio en los textos realizados por autores nacionales ya que el conocimiento matemático vertido allí, en particular lo relativo a medidas 
y SMD, era extractado y/o seguía muy de cerca el saber expuesto en ciertas obras extranjeras, de autores de renombre, que circularon en el país.

- Muchas de las obras didácticas que sirvieron para la introducción y difusión del SMD fueron escritas en la modalidad de catecismos (preguntas/respuestas); el tratamiento del tema era esencialmente de tipo calculístico, enfatizando en lo práctico, con abundantes ejercicios de cálculo destinados a la realización de reducciones más o menos prolijas entre las antiguas medidas y las nuevas, así como en las relaciones existentes entre una unidad, sus múltiplos y submúltiplos; el enfoque obligaba a un aprendizaje de tipo memorístico; asimismo, existía una notoria ausencia de ilustraciones así como de la explicación y uso de los instrumentos de medida.

- La introducción del SMD en la escuela, y en las obras didácticas, involucró cambios en la enseñanza de la aritmética, siendo el más notorio la preponderancia del estudio de las fracciones decimales y la pérdida de importancia de los números complejos o denominados, originando con ello una mayor destreza en los alumnos en lo relativo a las operaciones con las fracciones decimales.

- Una temática no discutida en este escrito es el papel de otras obras, como las que tratan de teneduría de libros, en este proceso de implantación del SMD. Tampoco fue abordado el interesante tema de la relación de la introducción del SMD con la conformación de la República.

- La dificultad de encontrar, para su respectiva consulta, buena parte del material original, es una dificultad intrínseca a este tipo de investigaciones.

\section{Referencias}

Abad, L. y otros. (1984). Organización y consolidación del sistema educativo (1830-1935). La educación en Venezuela 2. Caracas Centro de Reflexión y Planificación Educativa (CERPE).

Alvarado, L. (1023). Pesas y medidas usados en Venezuela. Revista del Colegio de Ingenieros de Venezuela, 1(2), 26-30. 
Arboleda, L. C. (2014). Introducción del Sistema Métrico Decimal en Colombia a mediados del siglo XIX. Cuadernos de Investigación y Formación en Educación Matemática, 9(12), 73-86.

Arboleda, L. C. (2015). Élites, medidas y Estado en Colombia en la primera mitad del siglo XIX. Orden republicano y sistema métrico decimal.En: H. Quinceno Castrillón (Comp.). La nación imaginada. Ensayos sobre los proyectos de nación en Colombia y América Latina en el siglo XIX. Cap. 5 (pp. 177-230). Cali: Universidad del Valle. Disponible en: http://www.digitaliapublishing.com/a/44052/.

Azorin, F. (1972). Curso de muestreo y aplicaciones. Madrid: Aguilar.

Barral, B. de (1979). Diccionario castellano-warao. Caracas: El Autor.

Barreto de Brito, J. F. (2017). A gestação do sistema métrico decimal no mundo e no Brasil. Anais do Encontro Nacional de História Política, Universidade Estadual do Ceará. Disponible en: http://uece.br/eventos/gthpanpuh/anais/edicao_2017.html.

Beyer K., W. O. (2012). Estudio evolutivo de la enseñanza de las matemáticas elementales en Venezuela a través de los textos escolares: 1826-1969. La Paz, Bolivia: Instituto Internacional de Integración Convenio "Andrés Bello"-Grupo de Investigación y Difusión en Educación Matemática (GIDEM).

Beyer K., W. O. (2013). La Aritmética de Romero y Serrano: Primer libro de matemáticas impreso en Venezuela. Paradigma, 34(2), 109-122.

Beyer K., W. O. (2016a). La influencia de Sylvestre-François Lacroix en la matemática venezolana decimonónica. HISTEMAT-Revista de História da Educação Matemática, 2(3), 229-255.

Beyer K., W. O. (2016b). Una excursión antropomatemática o la cuadratura de la rueda. Caracas: Grupo de Investigación y Difusión en Educación Matemática (GIDEM).

Beyer K., W. O. (2017). Análisis y comparación de dos obras de aritmética comercial en la venezuela decimonónica. En: Tulio Ramírez (Compilador). El Texto Escolar Diferentes Miradas, Cap. 1, (pp. 17-33). Caracas: Centro de Investigaciones Educativas. Escuela de Educación, UCV.

Bishop, A. (1999). Enculturación matemática. La educación matemática desde una perspectiva cultural. Barcelona, España: Paidós.

Bonfil Batalla, G. (1991). Lo propio y lo ajeno: Una aproximación al problema del control cultural. En G. Bonfil Batalla (1991). Pensar Nuestra Cultura (pp. 49-57). México D.F.: Editorial Patria.

Brito, O. (2002). Los libros de matemáticas en la Venezuela del siglo XIX. Trabajo de Grado de Licenciatura (no publicado), Universidad Central de Venezuela, Caracas.

Brito Figueroa, F. (2005). Historia económica y social de Venezuela. Tomo I. Caracas: Ediciones de la Biblioteca, Universidad Central de Venezuela.

Cagigal, J. M. (1839a). Pesas y medidas. Primer artículo. En: L. Correa (Comp.). (1956). Juan Manuel Cagigal. Escritos literarios y científicos (pp. 133-141). Caracas: Imprenta Nacional. 
Cagigal, J. M. (1839b). Pesas y medidas. Segundo artículo. En: L. Correa (Comp.). (1956). Juan Manuel Cagigal. Escritos literarios y cientificos (pp. 143-147). Caracas: Imprent Nacional.

Cardozo Galué, G. (s/f). Maracaibo en el siglo XIX. Historia para todos 2. Caracas: Historiadores SC.

Carlós, L. (2002). Algunas consideraciones en torno al análisis de textos escolares. Centro de Estudios en Investigación y Documentación Educativa (CEIDE). Disponible en: http://www.fhumyar.unr.edu.ar/ceide/a1.htm.

Castellanos, R. R. (2017a). Historia de las librerías en Venezuela (1607-1900). Tomo I. Caracas: Instituto Autónomo Centro Nacional del Libro.

Castellanos, R. R. (2017b). Historia de las librerías en Venezuela (1607-1900). Tomo II. Caracas: Instituto Autónomo Centro Nacional del Libro.

Chervel, A. (1991). Historia de las disciplinas escolares. Revista de Educación, 295, 59-111.

Chevallard, Y. (2000). La transposición didáctica. Del saber sabio al saber enseñado. Buenos Aires: Aique Grupo Editor.

Chiquito, M. (1842). Compendio de aritmética razonada segón Lacroix y otros autores. Caracas: Imprenta de "El Venezolano".

Chitty, G. (1868). Sistema métrico. Exposición completa, teórica i sobre todo práctica de este sistema, con tablas para las reducciones de las antiguas pesas i medidas a las nuevas y viceversa. Destinado especialmente al comercio $i$ a las escuelas de los Estados Unidos de Venezuela. Caracas: Establecimiento Tipográfico de Melquíades Soriano.

Choppin, A. (2000). Pasado y presente de los manuales escolares. En: Julio Ruiz Berrío (Ed). (2000). La cultura escolar en Europa. Tendencias históricas emergentes (pp. 107165). Madrid: Editorial Biblioteca Nueva.

Cohen, L. y Manion, L. (1990). Métodos de investigación educativa. Madrid: Editorial La Muralla.

Colubi, R. de (1978). Metrología. Caracas: Fondo de Desarrollo Metrológico, Servicio Nacional de Metrología Legal.

Congreso General de Colombia. (1821). Ley de 11 de octubre sobre uniformidad de pesos y medidas. En: Cuerpo de Leyes de la República de Colombia (1961) (pp. 95-96). Caracas: Universidad Central de Venezuela, Consejo de Desarrollo Científico y Humanístico.

Congreso de la República de Venezuela. (1857a). Ley del 13 de febrero de 1857. En: R. de Colubi. (1978). Metrología (pp. 133-134). Caracas: Fondo de Desarrollo Metrológico, Servicio Nacional de Metrología Legal.

Congreso de la República de Venezuela. (1857b). Ley del 13 de febrero de 1857. En: Academia de Ciencias Políticas y Sociales (1982). Leyes y Decretos de Venezuela 1851-1860. Tomo 3 (pp. 537-538). Caracas: Biblioteca de la Academia de Ciencias Políticas y Sociales.

Consejo de Instrucción del Distrito Federal. (1911). Programas provisionales de enseñanza primaria para las escuelas federales de la República. En: Ministerio de Instrucción 
Pública. (1912). Memoria de 1911. Tomo I (pp. 74 y sigs.). Caracas: Imprenta Nacional.

Coronado Millán, B. (1882). Aritmética práctica. Caracas: Imprenta Bolívar.

Crespo, J. M. (1803). Aritmética razonada. Escrito rara (SIC) niños. Cúcuta: Imprenta Liberty.

Dalmau Carlés, J. Ma. (1969). Aritmética razonada y nociones de álgebra. Tratado teóricopráctico demostrado. Gerona: Dalmau Carlés, Pla. S. A. Editores.

D’Ambrosio, U. (1986). Da realidade a ação. Reflexões sobre educação e matemática. São Paulo, Summus-Campinas: Editorial da Universidade Estadual de Campinas.

Durán, D. (2003). La geometría euclidiana. Maracaibo: Ediciones Astro Data S. A.

Echeandía, M. Mª (1896). Compendio de aritmética razonada. Extractada de los mejores autores para el uso de los jóvenes que asisten a los colegios y a las escuelas de primeras letras. Caracas: Librería Española.

Echeandía, M. Ma . (1926). Compendio de aritmética razonada. Extractada de los mejores autores para el uso de los jóvenes que asisten a los colegios y a las escuelas de primeras letras. Caracas: Librería Española.

Engels, F. (1978). El papel del trabajo en la transformación del mono en hombre. Medellín: Ediciones Hombre Nuevo.

Gómez, J. V. (1912). Decreto de 18 de mayo de 1912 por el cual se declara obligatoria en la República la práctica del sistema métrico decimal y su nomenclatura. En: Academia de Ciencias Políticas y Sociales (1993). Leyes y Decretos de Venezuela 1912. Serie República de Venezuela 35 (pp. 39-40). Caracas: Biblioteca de la Academia de Ciencias Políticas y Sociales.

González Raposo, Ma . del S. (1990). Orígenes de la medida. Mérida: Consejo de Desarrollo Científico, Humanístico y Tecnológico y Consejo Editorial de la Universidad de Los Andes.

Guzmán Blanco, A. (1870). Decreto de instrucción pública gratuita y obligatoria. En: R. J. Velásquez (Dir.). (1989). Documentos que hicieron historia 1810-1989. Vida republicana de Venezuela. Tomo II De la Revolución Azul a nuestros días (1868-1961) (pp. 22-35). Caracas: Ediciones de la Presidencia de la República.

Hölldobler, B. y Wilson, E. O. (2014). El superorganismo. Belleza y elegancia de las asombrosas sociedades de insectos. Buenos Aires/Madrid: Katz Editores/Clave Intelectual, S. L.

Ibarra, A. (1860). Compendio de aritmética. Teórica y práctica [Parte práctica]. Caracas: Imprenta de Jesús María Soriano.

Iradi, R. (1874). Aritmética comercial de reglas breves para todos los cálculos que se efectúan con los números. Caracas: Rojas Hermanos, Libreros-Editores.

Kula, W. (1980). Las medidas y los hombres. México: Siglo Veintiuno Editores.

Landaeta Rosales, M. (2006). Riqueza circulante en Venezuela. Caracas: Fundación La Casa de Bello.

Landáez, M. V. (1895). Tratado de Aritmética esencialmente práctica y nociones de sistema métrico decimal. Caracas: Tipografía Guttenberg.

Landáez, M. V. (1910). Tratado de Aritmética esencialmente práctica y nociones de sistema métrico decimal (Segunda edición aumentada y corregida). Caracas: Tipografía "La Religión". 
Librería Española. (1905). Catálogo de obras de fono y algunas de surtido de la Librería Española. Caracas: Tipografía de J. M. Herrera Irigoyen y CA.

Malo, R. (1847). Aritmética comercial para el uso de las escuelas de Venezuela. Caracas: Imprenta Boliviana.

Ministerio de Instrucción Pública. (1911). Resolución aprobando los Programas provisionales de enseñanza primaria para las escuelas federales de la República. Gaceta Oficial $N^{\circ}$ 11.483, del 9 de diciembre de 1911.

Ministerio de Relaciones Esteriores. (1862). Circular á los Gobernadores, ordenándoles que todos los Concejos Municipales dispongan la enseñanza del sistema métrico decimal de monedas, pesos y medidas, en las escuelas primarias, públicas y privadas. Registro Oficial, Año 1, $\mathrm{N}^{\circ} \quad 15, \quad 113-120 . \quad$ Disponible en: https://archive.org/details/gacetaoficialdel1861vene/page/114.

Montes, R. I. (1873). Compendio de aritmética práctica para las escuelas primarias. Caracas: Rojas Hermanos, Libreros-Editores.

Mosonyi, E. E. (2008). El indígena venezolano en pos de su liberación definitiva. Caracas: Fundación editorial el perro y la rana. Disponible en: http://www.elperroylarana.gob.ve/wpcontent/uploads/2017/08/el_indigena_venezolano_en_pos_de_su liberacion_definitiva .pdf.

Mosterin, J. (1981). Grandes temas de la filosofía actual. Colección Temas Clave, $N^{\circ} 56$. España: Salvat Editores.

Muñoz Tébar, J. (1897). Catecismo del sistema métrico decimal para el uso de las escuelas de la República. Caracas: Librería Española, L. Puig Ros y Hermano Libreros-editores.

Nuevo Testamento. Nashville, Tennessee: The Gideons International.

Pacheco, A. (1894). Guía práctica de reducciones de monedas y otras medidas al alcance de los niños. Caracas: Imprenta de "La Religión".

Páez Pumar, M. (1900). Aritmética práctica. Caracas: Tipografía Guttenberg/ Librería Moderna.

Picado Alfaro, M. E. (2012). El Sistema Métrico Decimal en libros de texto de matemáticas en España durante la segunda mitad del siglo XIX (1849-1892). Tesis doctoral, Universidad de Granada, España. Disponible en: https://hera.ugr.es/tesisugr/21610903.pdf.

Picado, M. y Rico, L. (2012). La introducción del sistema métrico decimal y los libros de texto en España. Suma, 71, 9-18.

Picado, M.; Rico, L. y Gómez, B. (2013). El Sistema Métrico Decimal en textos de matemáticas para la instrucción primaria en las Islas Canarias en el siglo XIX. Números, 82, 37-53.

Piñero Olivero, M. (1897). Tratado de aritmética elemental. Curaçao: Imprenta de la Librería de A. Bethencourt e Hijos.

Rodríguez Castillo, L. (2000). Pesas y medidas antiguas en Venezuela. Caracas: Fondo Editorial Tropykos.

Rojas Hermanos. (1875). Advertencia de los editores en la segunda edición. En: J. Muñoz Tébar (1897). Catecismo del Sistema Métrico Decimal para el uso de las escuelas de la República (pp. 5-6). Caracas: Librería Española, L. Puig Ros y Hermano LibrerosEditores. 
Romero y Serrano, L. Ma. (1842). Lecciones de aritmética, puestas en forma de diálogo. Caracas: Valentín Espinal.

Sánchez, M. S. (1946). Bibliografía de obras didácticas publicadas en Venezuela o por autores venezolanos en el extranjero. Caracas: Tipografía Americana.

Santa Biblia. (1960). Colombia: Sociedades Bíblicas Unidas.

Schubring, G. (1987). On the methodology of analysing historical textbooks: Lacroix as textbook author. For the Learning of Mathematics, 7(3), 4151.

Sistema Autónomo Nacional de Normalización, Calidad, Metrología y Reglamentos Técnicos (SENCAMER). Portal. Disponible en: http://www.sencamer.gob.ve/sencamer/documents/historia.htm.

Struik, D. (1960). La matemática. Sus orígenes y desarrollo. Buenos Aires: Siglo Veinte.

Talancón Escobedo, J. L. (2006). El Sistema Métrico Decimal y la lucha por la hegemonía mundial. Este País, $\mathrm{N}^{\circ}$ 185, 24-28. Disponible en: http://132.248.130.124/ejerciciost/sist.html.

Talancón Escobedo, J. L. (2008). Historia y sociología de la ciencia. Introducción. Universidad Nacional Autónoma de México, Secretaría de Desarrollo Institucional. Disponible en: http://132.248.130.124/ejerciciost/intro.html.

Torrealba, G. (2018). Las estaciones sarrapieras: los Mapoyo y las economías extractivas del Orinoco Medio, Venezuela. Boletim do Museu Paraense Emilio Goeldi. Ciências Humanas, 13(2). Documento en línea. Disponible en: https://www.redalyc.org/jatsRepo/3940/394056633003/html/index.html.

Travers, Robert. (1986). Introducción a la investigación educacional. Barcelona, España: Ediciones Paidós.

Urdaneta, R. (1997). Diccionario general de los indios Cuicas. Trujillo-Caracas: Sociedad de Amigos de la Biblioteca Pública "Mario Briceño Iragorry".

Vallejo, J. M. (1840). Explicación del sistema decimal, ó métrico francés. Madrid: Imprenta de Garrasallaza-Librería de la Publicidad. Disponible en: http://www.adurcal.com/enlaces/mancomunidad/guia/persohisto/vallejo/index.htm.

Viedma C., J. A. (s/f). Lecciones de geometría intuitiva. Colombia: Editorial Norma-McGrawHill.

Vilda, C. (1997). Proceso a la cultura en Venezuela III. Siglo XX. Curso de Formación Sociopolítica, 31. Caracas: Fundación Centro Gumilla.

Villegas, G. T. (1974). Instrucción popular. En: R. F. Seijas (Comp.) (1974). Primer libro venezolano de literatura, ciencias y bellas artes (pp. 55-63). Caracas: Concejo Municipal del Distrito Federal.

Zumeta, C. (1914). Resolución de 13 de febrero de 1914 por la cual se reglamenta el uso y práctica del sistema métrico decimal. En: Academia de Ciencias Políticas y Sociales (1994). Leyes y Decretos de Venezuela 1914. Serie República de Venezuela 37 (pp. 41 45). Caracas: Biblioteca de la Academia de Ciencias Políticas y Sociales. 
Walter O. Beyer K.

Doctorado en Educación, con énfasis en Educación Matemática. Magister en Enseñanza de la

Matemática, Licenciado en Matemáticas. Ex Presidente de la Asociación Venezolana de Educación Matemática. Área principal de investigación: Historia de las Matemáticas y de la Educación Matemática en Venezuela. Universidad Nacional Abierta, Caracas, Venezuela. ORCID: 0000-0003-1726-7994.E-mail: nowarawb@gmail.com 